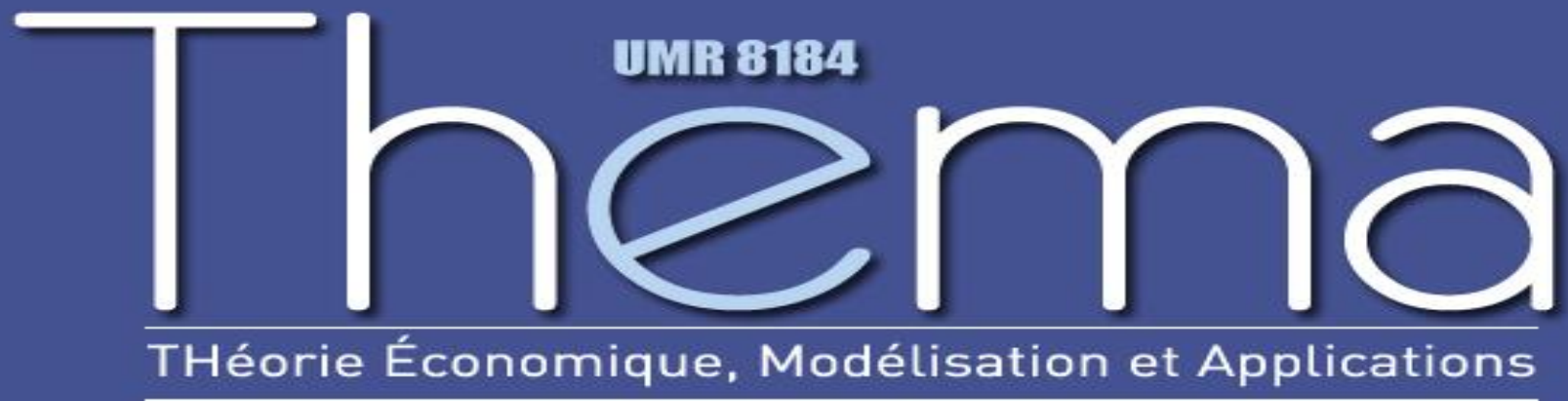

Thema Working Paper $\mathrm{n}^{\circ}$ 2010-04 Université de Cergy Pontoise, France

Education and the welfare gains from employment protection

Charlot Olivier

Malherbet Franck

September, 2010 


\title{
Education and the welfare gains from employment protection*
}

\author{
Olivier CHARLOT ${ }^{\dagger}$ and Franck MALHERBET ${ }^{\ddagger}$
}

September 2010

\begin{abstract}
In this paper, we generalize the study of the return to education undertaken in e.g. Laing, Palivos and Wang (1995) or Burdett and Smith (2002) to an environment where the link between education and employment stability is taken into account. This enables us to study how an European-like and Employment Protection Legislation (EPL) with heavily regulated long-term contracts and more flexible short-term contracts affects the return to schooling, equilibrium unemployment and welfare. In this context, we show that firing costs and temporary employment have opposite effects on the rate of use of human capital and thus, on educational investments. We furthermore demonstrate that a laissez faire economy with no regulation is inefficient as it is characterized by insufficient educational investments leading to excess job destruction and inadequate job creation. By stabilizing employment relationships, firing costs may spur educational investments and therefore lead to welfare and productivity gains, though a first-best policy would be to subsidize education. However, there is little chance for a dual (European-like) EPL to raise the incentives to schooling and aggregate welfare.
\end{abstract}

Keywords human capital; job destruction; matching frictions; efficiency

JEL Classification I20; J20; J60

\footnotetext{
${ }^{*}$ We are grateful to participants to APET and EALE 2009 conferences for useful comments. The paper has also benefited from helpful remarks by Bruno Decreuse, Olivier L'Haridon and Fabien Moizeau and seminar participants at THEMA, University of Cergy-Pontoise and CREM, University of Rennes. The usual disclaimer applies.

${ }^{\dagger}$ Université de Cergy-Pontoise, THEMA, F-95000 Cergy-Pontoise. Email: ocharlot@u-cergy.fr

${ }^{\ddagger}$ Université de Cergy-Pontoise, THEMA, F-95000 Cergy-Pontoise, IZA and fRDB. Email : franck.malherbet@u-cergy.fr
} 


\section{Introduction}

Many European countries are characterized by dual employment protection which is akin to the coexistence of both stable/long-term jobs (hereafter, LTJ), which benefit from stringent protection, and unstable/short-term jobs (STJ) with a short duration and little or no protection. In this paper we study the link between education and employment stability when the economy is regulated by an European-like employment protection legislation (EPL). We aim at answering the following questions: What are the effects of this type of dual EPL on education investments, and how do the various features of European EPL distort the return to schooling ? What are the effects of dual EPL on aggregate unemployment and welfare when the reaction of education investments are accounted for?

To the best of our knowledge, the consequences of those links between education and the various aspects of job (in)stability on the return to education have been neglected so far. This paper is aimed at filling this gap.

Our motivations for this study are twofold. First, since the seminal work by Jacob Mincer (1991), it is well-known that one of the benefits of education is a lower probability of being fired, i.e. the higher a worker's education level, the lower the chance of job destruction. Additional evidence of a similar link are documented in various studies, such as e.g. Cohen, Lefranc and Saint-Paul (1997) for France and the US. Second, dual EPL is prevalent in many European countries. Such regulations introduce counteracting effects on job stability, as they reduce job destruction for stable jobs, but may increase job instability for short-term jobs. At the same time, education investments are linked to job stability and react to changes in labour market regulations.

With these features in mind, we develop an analysis of the return to education in an equilibrium search-matching model similar in spirit to Laing, Palivos and Wang (1995) or Burdett and Smith (2002). We depart from these authors by introducing endogeneous job destruction in a framework à la Mortensen and Pissarides (1994), further extended to account for the main characteristics of EPL in Europe: firms can hire only a fraction of the workers on a short-term (rather than long-term) basis due to legal restrictions, with virtually no firing penalty when STJ are not converted into LTJ $^{1}$. This captures the two main features of dual EPL through two simple policy parameters, the proportion of new hires on STJ who do not initially benefit from stringent EPL but can be converted into LTJ after a certain duration, and the amount of firing costs induced by administrative procedures, applying only to LTJ. This setting enables us to study the impact of labour market institutions -dual labour contracts and firing costson endogeneous job creation, job destruction and human capital investments, and consequently appears relevant to our purpose. In addition, it admits the competitive equilibrium without frictions as a limit case when search frictions die down. In this particular case, the labour market is similar to the competitive labour market considered in Becker (1964) where the only

\footnotetext{
${ }^{1}$ This way of modelizing dual EPL has become quite conventional. See e.g. Cahuc and Postel-Vinay, 2002, Cahuc and Malherbet, 2004, Sala et al. 2008, Bentolila et al. 2009. Further discussion on alternative modelling assumptions of STJ are provided in section 3, while detailing the model.
} 
incentive to invest in education is to raise one's productivity and wage, and where the labour market is fully efficient. In the more general (frictional) case considered here, we bring together two strands of the literature, which can be broadly depicted as follows:

i. the literature on education and unemployment highlights a number of benefits from education and the existence of various distortions related to education decisions in frictional labour markets. This literature generally investigates the link between education and exit from, rather than entry into unemployment (see among others, Saint-Paul, 1996, Snower, 1996, Moen, 1999, Charlot, Decreuse and Granier, 2005) as is the case in this paper.

ii. the literature dealing with labour labour market regulations generally concentrates on exogeneous education/skill level (e.g. Mortensen and Pissarides, 1999, Blanchard and Landier, 2002, Cahuc and Postel-Vinay, 2002).

To begin with, we complement the first strand by focusing on the link between general education and entry into unemployment. Our analysis shows that one of the beneficial effects of employment protection is to stabilize employment relationships, which can be beneficial to human capital investments, by increasing the rate of use of human capital. However, a dual EPL introduces a conflicting effect on education. Namely, a rise in the proportion of temporary contracts reduces the incentives to schooling: temporary jobs are more likely to be destroyed, and job instability reduces the rate of use of human capital, which is detrimental to human capital investments. In addition, a more stringent employment protection reduces the incentives to convert temporary jobs into permanent contracts, which further increases jobs instability and reduces the incentives to schooling.

In this framework, firing costs can be beneficial to equilibrium human capital investments, while a rise in the proportion of short-term jobs can be detrimental. We hence highlight a novel educational effect and show for fairly reasonable configurations that an European-like labour market EPL exerts conflicting effects on the workforce education level. In particular, the effect of firing costs on job creation is found to be ambiguous in general, because the usual negative effect on job creation can sometimes be outweighed by a positive effect on education and productivity fostering job creation. The usual positive impact of EPL on job stability can be further reinforced by the fact that job stability spurs educational investments, which further improves job stability. In addition, the global effect of firing costs on unemployment is found to be ambiguous in general, but could lead to a fall in unemployment, especially when the positive education effect dominates, as education stimulates job creation and reduces job destruction. Computational illustrations show that the usual (negative) effect of firing costs on job creation dominates when education investments are not very responsive to changes in job stability, while the positive effect may dominate in some cases, when education is more responsive. In this case, our simulations show that the overall impact of firing costs on unemployment can be expected to be a reduction in unemployment, while a rise in the share of temporary jobs leads to a rise in unemployment. The fall (rise) in unemployment induced by firing costs (temporary jobs) can be expected to be larger when investments are more responsive to changes in job stability.

In addition, given the strategic complementarities between education and job creation, more 
than one equilibrium may result. Though this is a common result in matching models with educational investments, it is here extended to the case of endogeneous job destruction. In some cases, it can also be shown that a low-skill trap may result from large firing costs, whereas the trap becomes less likely when there are more temporary jobs.

Finally, we complement the second strand by focusing on the effects of a dual EPL on equilibrium and welfare when education investments are taken into account. In particular, it is worth noting that our framework gives an explicit rationale for employment policies. Our results can then be compared with the literature which considers productivity/education as given. We thus investigate the welfare properties of the equilibrium. We show that the laissez faire equilibrium without EPL is inefficient, characterized by insufficient educational investment leading to too few job creations and too many job destructions. This is at odds with a large part of the literature where education is not considered and where there are in general too few job destructions compared to the optimum when the Hosios (1990) condition does not hold ${ }^{2}$. Therefore, in some cases, EPL in the form of firing costs can be welfare improving by stabilizing employment relationships and stimulating human capital investments, though the first best policy remains an education policy aimed at subsidizing education efforts. Note however that there is little chance for a dual labour market to be welfare improving, given its negative impact on education investments and job stability which should be compensated by a large rise in job creation. In this respect, the conclusion of Blanchard and Landier (2002) and Cahuc and Postel-Vinay (2002) on the negative impact of dual employment protection on welfare seems to be relatively robust.

The organization of the paper is as follows: Section 2 discusses a few stylized facts relevant to our study, while section 3 offers a deeper review of the related literature. Section 4 depicts the basic setup. Section 5 studies the partial equilibrium properties of the model and section 6 its general equilibrium properties. In section 7 we provide some numerical exercises aimed at quantifying the various effects. Section 8 studies the normative properties of the model. Finally, section 9 concludes.

\section{Stylized Facts}

The extensive recourse to short term jobs (STJ) is a striking feature of labour markets with rigorous EPL. This type of contracts accounts for 10 to $30 \%$ of total employment and for a substantial proportion of new hires, representing up to $90 \%$ in "rigid" countries like Spain. It is now widely acknowledged that the specific regulations of (Continental) European labour markets have increased employment instability through a series of marginal reforms that liberalized the use of fixed-term and atypical employment contracts (OECD, 2004).

As the scatter-plot below illustrates, STJ are used to increase labour market flexibility. One obvious reason for the positive relationship between firing costs and the share of STJ stems from the fact that the probability to convert a temporary job into a permanent one is lower

\footnotetext{
${ }^{2}$ see e.g. Caballero and Hammour, 1996, and Pissarides, 2000.
} 
when firing costs are high. Indeed, as reported by the OECD (2002), a non-negligible fraction of those temporary jobs can be transformed into permanent contracts in some countries with low EPL like the UK, where the transformation rate is about $50 \%$, while it is much lower in countries with more stringent EPL like France, where the proportion is close to $20 \%$. As a result of those declining incentives to transform temporary contracts into permanent contracts with EPL strictness, STJ appear as stepping stones in some countries and look a bit more often like dead ends in others (see e.g. Booth, Francesconi, and Frank, 2002, Dolado, Garcia-Serrano and Jimeno, 2002).

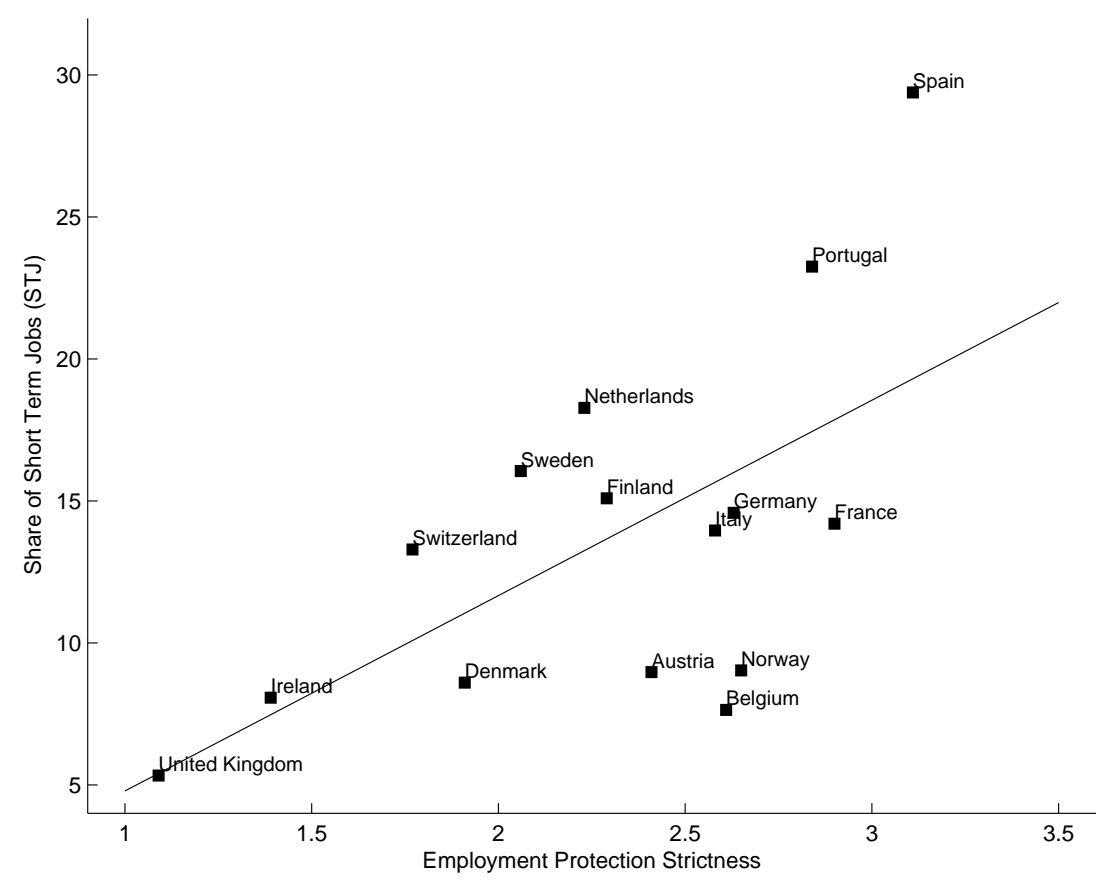

Figure 1: The relation between the share of temporary employment and the stringency of EPL. Source: OECD(2008).

As a whole, the extensive use of STJ has contributed to increase job instability as proved by the large proportion of separations resulting from STJ terminations rather than layoffs or quits. The table below reports some evidence for the French labour market in 2006.

\begin{tabular}{lr}
\hline \hline Terminations of Short Term Jobs (STJ) & 56.7 \\
Quits & 16.8 \\
Layoffs & 7.8 \\
Retirement & 3.4 \\
Other reasons & 15.3 \\
\hline \hline
\end{tabular}

Table 1: Employment termination by reason (in \%). Source: DARES, DMMO/EMMO. Data summary is also available in "Dares Première Synthèse", 07.1, February 2008. 
From Table 1, it is straightforward to remark that STJ terminations accounts for more than $50 \%$ of total separations whereas the share of quits and layoffs in the separations accounts for less than 25\%. Furthermore, it has induced many perverse effects with doubtful outcomes. In particular, it has been argued that dual labour markets may lead to higher rather than lower unemployment and may also be detrimental to efficiency (e.g. Blanchard and Landier, 2002, Cahuc and Postel-Vinay, 2002).

At the same time, STJ are probably more of a problem for less educated workers than for their more educated counterpart. Namely, the empirical evidence shows that the probability to be employed on a long-term rather than on a temporary (short-duration) contract increases on average with the workers' education level. Table 2 suggests the existence of such a link based on French data for 2004 collected by CEREQ:

\begin{tabular}{lcc}
\hline \hline & $\begin{array}{c}\text { Percentage hired on a } \\
\text { long term contract (CDI) } \\
\text { as a first job }\end{array}$ & $\begin{array}{c}\text { Percentage working on a } \\
\text { long term job (CDI) after } \\
\text { three years of working life }\end{array}$ \\
\hline No degree & 23 & 45 \\
Vocational degree & 28 & 59 \\
Secondary education, general & 25 & 57 \\
Basic tertiary education & 29 & 70 \\
University degree, undergraduate & 35 & 68 \\
University degree, graduate & 40 & 74 \\
\hline Overall & $\mathbf{3 0}$ & $\mathbf{6 3}$ \\
\hline \hline
\end{tabular}

Table 2: Job destruction and schooling investment. Source: CEREQ data from the survey "Enquête génération 2004" on a sample of youth having left school in 2004. Data summary is also available in "CEREQ Bref", 248, January 2008.

From both columns of this table, it appears that the higher a worker's education level, the larger the probability to be employed on a long-term rather than on a short-term contract. A similar relationship holds for many/most European countries as Figure 2 hereafter illustrates ${ }^{3}$.

It is worth remarking that the proportion of workers employed on STJ decreases with the education level in most countries. Additional evidence suggests that when hired on a STJ, the probability to see a short-term (temporary) contract converted into a permanent one increases on average with the worker's education ${ }^{4}$ (Guell and Petrongolo, 2007, and OECD, 2002), a fact that is also consistent with the observation highlighted above. Still, this probability is affected by the stringency of EPL, i.e. the stricter EPL, the lower the conversion rate for a given level of education and a large part of our analysis is dedicated to the study of the impact of EPL on

\footnotetext{
${ }^{3}$ See also Bentolila and Dolado (1994) who show that low-skill workers are over-represented in temporary employment.

${ }^{4}$ The figures presented here are aimed at illustrating our purpose. Of course, controlling for characteristics other than education as for unobserved heterogeneity would be more suggestive of a causality. This is done for instance in Guell and Petrongolo (2007).
} 


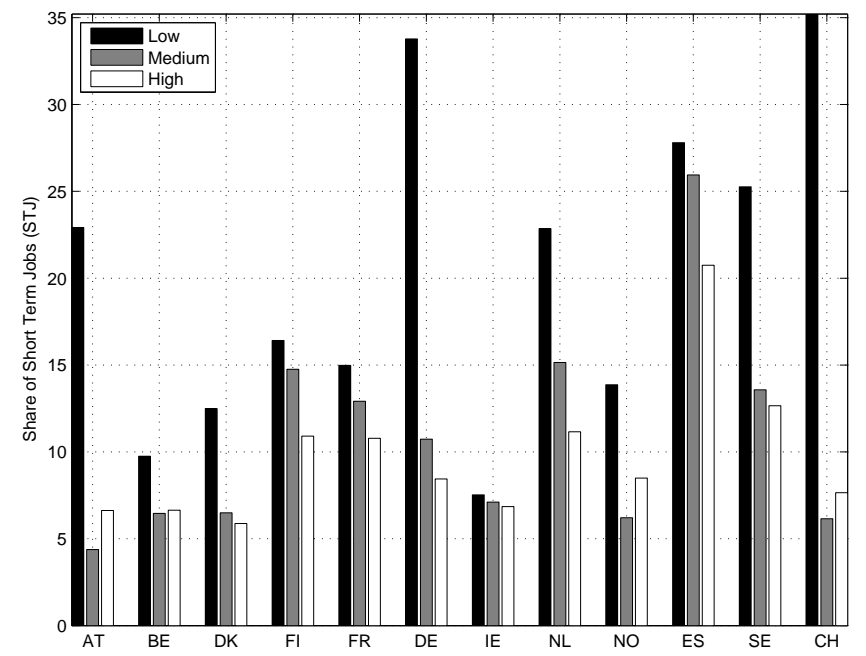

Figure 2: Share of temporary workers in total employment for various education levels. Education levels are decomposed according to the International Standard Classification of Education $(\mathrm{UNESCO}, 1997)$. Low $=$ Pre-primary, primary and lower secondary education; Medium $=$ Upper secondary and post-secondary non-tertiary education; High = Tertiary education. Source: EUROSTAT (2008).

the incentives to schooling. 


\section{Related literature}

Our paper is primarily related to the literature on education and frictional unemployment. By and large, the literature in this field divides into two strands. In the first strand, insufficient educational investments are generally highlighted (e.g. Laing, Palivos and Wang, 1995, Acemoglu, 1996, Burdett and Smith, 2002) while in the second, overeducation may take place (Saint-Paul, 1996, Moen, 1999, Charlot, Decreuse and Granier, 2005, Charlot and Decreuse, 2005). This paper is clearly mostly related to the first strand. A key novelty compared to those papers is to generalize the analysis of the return to education to an environment where labour market institutions (in the form of dual EPL) and employment stability are accounted for, while most if not all of the literature proceeds with exogeneous or no job destruction. This enables us to highlight the impact of EPL on the incentives to schooling and to show that in some cases, firing costs can be welfare improving by stabilizing employment relationships and raising the incentives to schooling whereas the divide between short-term and long-term contracts induces the opposite.

Our paper can also be related to the many papers studying the impact of EPL on equilibrium unemployment and welfare, such as e.g. Mortensen and Pissarides (1999). Firing costs are often blamed for being responsible of sclerotic European labour markets, with an ambiguous impact on the unemployment rate, but a positive impact on unemployment duration and a negative impact on welfare by lowering job reallocations (e.g. Caballero and Hammour, 1996, and Pissarides, 2000). Compared to those contributions, our paper makes it clear that the impact of EPL on equilibrium unemployment depends on how educational investments react to changes in EPL. Given the opposite impact of firing costs and dual labour contracts on investments, there is however probably not much to gain from an European type of EPL in terms of human capital investments and aggregate unemployment. Our welfare analysis also shows that the hold up problem associated to those investments may justify the existence of firing costs.

Our analysis also bears some common feature with the good job/bad job problem highlighted in several papers such as Acemoglu (2001). In this paper, a hold-up problem is highlighted which may give rise to insufficient physical capital investments, and too many bad jobs. A similar "bad job problem" arises in our paper, with a few differences however. First, the difference between good and bad jobs is entirely due to EPL in our setting. Second, some of the temporary ("bad") jobs can be transformed into permanent ("good") jobs, which is in line with a large strand of the empirical literature where it is investigated whether temporary jobs are "stepping stones or dead ends" (e.g. Booth, Francesconi, and Frank, 2002, Dolado, Garcia-Serrano and Jimeno, 2002). Third, we do not take physical capital but rather human capital investments into account. In our setting, insufficient educational investments compared to the social optimum imply that too few temporary ("bad") jobs are transformed into permanent ("good") jobs. Fourth, job destruction is endogeneous in our setting, and it seems natural to think of bad jobs as jobs being more easily destroyed than good jobs.

Several other papers have also elaborated on the consequences of the hold-up problem arising with search frictions, ex ante investments and ex post Nash bargaining, such as Acemoglu (1996), 
Masters (1998), Acemoglu and Shimer (1999). We complement the literature on this topic by incorporating endogeneous job destruction and a dual employment protection system. It should also be noted that as highlighted by Acemoglu and Shimer (1999), a market mechanism may solve the hold-up problem in some cases, when investments are fully observable and when there exists a complete set of labour markets. This also applies to our framework, where no corrective policy would be needed in such a case, though we believe full observability and/or market completeness may be quite strong assumptions in some cases. Those caveats should nevertheless be borne in mind.

Our model provides some rationale to employment protection policies. Alternative explanations for the existence of firing costs can be found in e.g. Pissarides (2001) and Bertola (2004) who rely on risk aversion and imperfect insurance market, two features that are not considered here. Our model can be most closely related to Booth and Zoega (2003) and Belot, Boone and van Ours (2007) who rely on a human capital externality to account for the existence of firing costs. Three main differences with our setup can be noticed: first, they consider an on-the-job, firm-specific training investment rather than a general education investment undertaken at the beginning of the worker's life. Second, both of those models do not consider search frictions explicitly as a source of potential market failure. Third, we also try to analyze some of the positive and normative implications of a dual EPL, while they focus on the welfare effects of firing costs solely.

\section{The model}

\subsection{Preliminary assumptions}

Our aim is to examine the impact of the two main characteristics of employment legislation in European countries - red tapes and legal costs, and dual employment contracts in the form of temporary vs. long term (stable) jobs - on education investments. In this purpose, we appeal to an equilibrium unemployment model initially elaborated by Mortensen and Pissarides (1994, 1999). The framework is extended to incorporate heterogeneity in the type of labour contracts (temporary/permanent jobs) and endogeneous schooling. Our focus is on steady states.

Time is continuous. Workers are born at rate $\delta$ and face a constant risk of dying $\delta$ so that the size of the population is held constant and can be normalized to unity. Workers are assumed to be risk neutral. Let $\rho$ denote the pure rate of time preference and the interest rate of the economy, so that the global discount rate is $r=\rho+\delta$.

Education: The quantity of general human capital acquired by a worker depends on the amount of education effort $e$ undertaken at the beginning of the worker's life. Educational investments take the form of a costly effort, i.e. a worker willing to get the education level $e$ can reach a productivity $y(e)$, equally valuable at all firms irrespective of the type of labour contract. Education is acquired at the expense of a schooling cost $c(e)$. We shall assume $y($.$) to be twice$ continuously differentiable, with $y^{\prime}>0$ and $y^{\prime \prime}<0$. It should further be assumed that it satisfies 
the boundary conditions $y(0)=0, \lim _{z \rightarrow 0} y^{\prime}(z)=+\infty$ and $\lim _{z \rightarrow+\infty} y^{\prime}(z)=0$. The function $c($.$) is$ twice continuously differentiable, with $c^{\prime}>0$ and $c^{\prime \prime} \geq 0$, and satisfies the boundary conditions $c(0)=c^{\prime}(0)=0$ and $c(\infty)=\infty$.

Those assumptions imply decreasing return to education at the individual level. Note that we shall abstract from on-the-job learning or human capital losses following job destruction for the clarity of our argument. Immediately after the education stage, workers enter the labour market where they have to find a job.

Matching: Searching for a job and matching with a worker are costly activities. Vacant jobs and unemployed workers are brought together in pair by the customary matching function which relates the number of hires in the market to the total number of job seekers and vacancies, i.e. $M \equiv m(U, V)$ where $U$ and $V$ correspond respectively to the mass of job seekers and to the mass of vacancies which will be endogenized in equilibrium. The function $m$ is twice continuously differentiable, increasing and concave in both of its argument, linearly homogeneous and satisfies the Inada conditions and the boundary conditions $m(0, V)=m(U, 0)=0$ for $U, V \geq 0$. On average, a firm contacts a worker at rate $M / V$ while a job seeker meets a firm at rate $M / U$. Let $\theta=V / U$ be the labour market tightness. Linear homogeneity of the matching function allows to write those contact rates as $M / V=\eta(\theta)$ and $M / U=\mu(\theta)$. Contact rates $\eta(\theta)$ and $\mu(\theta)=\theta \eta(\theta)$ are decreasing and increasing functions of $\theta$ respectively.

Production: There is a large number of small firms, the number of which will be endogenized in equilibrium. Each firm is endowed with a single vacancy. When a match occurs, the firm produces with a fixed coefficient technology, requiring one worker with education level $e$ to produce $y(e)+x$ units of output. In this setup $x$ is the firm-specific productivity component, while $y(e)$ is worker-specific, and can be related to education. We assume that the match-specific component of every new match starts with productivity $x_{0}{ }^{5}$. Productivity then evolves according to a Poisson process with an arrival rate $\lambda$. A productivity shock consists in a random draw from a stationary and known-by-all distribution $G$ with support $\left[x_{l}, x_{u}\right]$. Following a shock, some matches may become unprofitable, as productivity may reveal too low compared to each of the parties' outside opportunities net of the relevant costs of terminating the match, in which case it is endogeneously dissolved.

Contracts and employment legislation (EPL): When matching with a firm, a job-seeker can be hired either on a temporary (short-term) or a stable (long-term) contract. The main difference is that long-term contracts are regular types of jobs - they can be terminated at the expense of a firing penalty $f$ - while temporary contracts are less protected - for the sake of simplicity, we shall assume they can be terminated at no cost. It is possible to convert a temporary job into a permanent one when it is profitable to do so. STJ can be either converted or

\footnotetext{
${ }^{5} \mathrm{~A}$ similar assumption is adopted by Blanchard and Landier (2002) or Cahuc and Malherbet (2004). Though this is not crucial, this implies that productivity can increase with seniority.
} 
destroyed upon the first change in productivity ${ }^{6}$. As will be shown in this paper, the incentives to transform a STJ decrease with the level of firing costs, which may have important consequences on education decisions.

The hiring process and production technology are assumed to be the same for both types of contracts. The alternative assumption is that search can be directed toward one particular type of contract, as in Garibaldi and Berton (2006). However, it may be argued that in reality, workers from different education levels are likely to be found on both types of contracts, as Table 2 (see previously) reveals. That is why we make the assumption that search is random ${ }^{7}$.

Firms would systematically prefer to hire workers on a short term basis ceteris paribus. However, as in Cahuc and Postel-Vinay (2002), we shall assume that hiring on a temporary basis is regulated, so that only a proportion $p$ of new hires are granted to be made on a temporary contract, the remaining $(1-p)$ are thus hired on a longer-term basis. It is also assumed that the type of contract is not known before the firm and the worker match. Those assumptions are consistent with the fact that a certain fraction of temporary jobs are converted into more stable jobs, at least after a certain duration, and despite potentially large firing costs when it is profitable to do so $^{8}$.

Firing costs $f$ paid by firms are not transferable to the workers and therefore consist in red tapes and legal costs rather than severance payments. This assumption is justified on two grounds: (i) Pure transfers in case of separation are offset by the wage negotiation process and do not affect creation and destruction margins (Lazear, 1990) ${ }^{9}$; (ii) Termination costs in the form of red tapes and legal costs significantly exceed severance payments (Blanchard, 2000 or Kramarz and Michaud, 2004).

Overall, those assumptions are globally in line with the characteristics of European labour market legislation. Dualism mainly results from a series of marginal reforms that liberalized the use of temporary and atypical contracts and fostered dual systems where both stable and temporary jobs coexist. It follows that EPL arises in a very particular way in such labour markets because there are both stable (long-term) jobs with restrictive administrative procedures and heavy judicial protection and unstable (short-term) jobs with trifling or at best little protection $^{10}$.

\footnotetext{
${ }^{6}$ Renewal of temporary jobs is ruled out, but this is mainly a shortcut. Our main conclusions still hold provided temporary jobs remain less stable than long-term jobs.

${ }^{7}$ Note also that job destruction is exogenous in Garibaldi and Berton (2006), so that the distortions induced by firing costs are not considered in their setting, which is the topic of this paper.

${ }^{8}$ Therefore, Dual EPL implies that job stability improves with seniority, as documented by Farber (1999).

${ }^{9}$ More accurately, Lazear (1990) emphasizes that, in the absence of contractual frictions, severance payments can be canceled out by an appropriate wage contract. This assumption is not restrictive to the extent that our framework is exempt of such frictions. See Garibaldi and Violante (2005) for more details on this topic.

${ }^{10}$ Alternative modeling assumptions for temporary jobs have been studied in the literature. For instance, in Bentolila and Saint-Paul (1992), Bentolila and Dolado (1994), or Wasmer (1999), firms can create both permanent and temporary jobs, but temporary jobs cannot be converted into permanent contracts. In Blanchard and Landier (2002), all new jobs are temporary and can be converted into stable jobs when a productivity shock occurs. In our model, this corresponds to the particular case where $p=1$. Our assumption is relevant to European countries' hiring procedures where only a share of new jobs are created on a short-term basis, mainly due to legal restrictions.
} 
Wages. Wages are the outcome of a Nash bargain, and are related to the productivity of a match as to firms' and workers' outside options. A few remarks are in order. (i) Nash bargaining implies that wages depend on each of the parties'outside options. In turn, outside options partly depend on the design of EPL. As a result, dual EPL implies different wages for the workers depending on their status: short-term contracts are exempt of firing costs, while firing costs apply to long-term contracts, but only once the worker is definitively hired. Thus, for long-term contracts, it is necessary to distinguish between the initial wage negotiated upon first negotiation and the wages renegotiated once the worker is hired. In the former case, EPL does not apply to the worker since he has not been definitively hired yet and the firm does not incur any firing cost in case of disagreement, whereas EPL applies when the wage is renegotiated, in the event of a productivity shock. (ii) Nash bargaining implies some degree of rent sharing. This implies suboptimal educational investments, a problem that can sometimes be alleviated by some degree of employment protection, as will be shown in this paper.

Hiring and firing decisions depend on the asset values and surpluses associated to each option, defined in the next subsection.

\subsection{Asset equations, Surpluses and bargaining}

Asset values can be defined as follows. Let $\Pi^{v}, \Pi^{t}, \Pi^{n s}$ and $\Pi^{s}$ denote the value to the firm of a vacant, a temporary, a new stable or a stable job respectively. In the same way, let $W^{u}$, $W^{t}, W^{n s}$ and $W^{s}$ denote the value to the worker of searching for a job, of being employed on a temporary, new stable or stable job respectively.

For any type of job, it is worth considering the associated surplus defined as the sum of the value of the job to the worker and the firm net of their outside options. Let us thus denote by: $\Omega^{t}, \Omega^{n s}$ and $\Omega^{s}$ the surplus from a temporary, new stable and stable job respectively.

The difference between the three types of surpluses is due to EPL. Temporary contracts are exempt of firing costs, so that the relevant outside option of the firm is simply $\Pi^{v}$. Stable jobs are subject to stricter EPL, so that the firm outside option is $\Pi^{v}-f$ given that the firm will have to pay a firing penalties if she decides to terminate the job. For new stable jobs, EPL will only apply once the worker is hired, which is not the case at the time negotiation takes place. Thus the relevant outside option for the firm in this case is $\Pi^{v}$. This implies the following expressions for surpluses:

$$
\begin{gathered}
\Omega^{s}(x, e)=\Pi^{s}(x, e)-\Pi^{v}+W^{s}(x, e)-W^{u}+f \\
\Omega^{n s}(x, e)=\Pi^{n s}(x, e)-\Pi^{v}+W^{n s}(x, e)-W^{u} \\
\Omega^{t}\left(x_{0}, e\right)=\Pi^{t}\left(x_{0}, e\right)-\Pi^{v}+W^{t}\left(x_{0}, e\right)-W^{u}
\end{gathered}
$$

Wages are the outcome of a Nash bargain which splits the surplus of a job according to the worker's and the firm's bargaining power denoted respectively by $\beta$ and $1-\beta$. Wages are also revised each time a productivity shock occurs, so that the surplus is split in fixed proportion at all dates. Bargaining over surpluses implies:

$$
\beta\left(\Pi^{s}(x, e)-\Pi^{v}+f\right)=(1-\beta)\left(W^{s}(x, e)-W^{u}\right)
$$




$$
\begin{aligned}
& \beta\left(\Pi^{n s}(x, e)-\Pi^{v}\right)=(1-\beta)\left(W^{n s}(x, e)-W^{u}\right) \\
& \beta\left(\Pi^{t}\left(x_{0}, e\right)-\Pi^{v}\right)=(1-\beta)\left(W^{t}\left(x_{0}, e\right)-W^{u}\right)
\end{aligned}
$$

Asset values can then be defined as follows. For firms, we have:

$$
\rho \Pi^{v}=-\gamma+\eta(\theta) \mathbb{E}_{e}\left[p \max \left\{\Pi^{t}, \Pi^{v}\right\}+(1-p) \max \left\{\Pi^{n s}, \Pi^{v}\right\}-\Pi^{v}\right]
$$

Holding a vacancy involves a flow $\operatorname{cost} \gamma$ and returns a worker at rate $\eta(\theta)$. Given that the firm does not know a priori the education level of the incoming worker, the value of matching with a worker has to be considered in expectations in the expression above, hence the expectation operator $\mathbb{E}_{e}$. When a contact occurs, the employer-worker pair discovers the type of contract that will be offered. A proportion $p$ of the workers can be hired on temporary contracts (indexed by $t$ ), while the remaining $1-p$ can be hired on new stable jobs (indexed by $n s$ ).

$$
r \Pi^{t}\left(x_{0}, e\right)=x_{0}+y(e)-w^{t}\left(x_{0}, e\right)+\lambda\left[\int \max \left\{\Pi^{n s}\left(x^{\prime}, e\right), \Pi^{v}\right\} \mathrm{d} G\left(x^{\prime}\right)-\Pi^{t}\left(x_{0}, e\right)\right]
$$

Temporary jobs filled with a worker whose education level is $e$ have a productivity $y(e)+x_{0}$, and pay a wage $w^{t}\left(x_{0}, e\right)$. They can be hit by a productivity shock at a rate $\lambda$ in each case. In the event of an adverse productivity shock, temporary jobs can be destroyed at no cost. If productivity is sufficiently high, they can be converted into (new) stable jobs.

$$
r \Pi^{n s}(x, e)=x+y(e)-w^{n s}(x, e)+\lambda\left[\int \max \left\{\Pi^{s}\left(x^{\prime}, e\right), \Pi^{v}-f\right\} \mathrm{d} G\left(x^{\prime}\right)-\Pi^{n s}(x, e)\right]
$$

New stable jobs filled with a worker whose education level is $e$ and whose match specific parameter is $x$ have a productivity $x+y(e)$, and pay a wage $w^{n s}(x, e)$. They are hit by a productivity shock at a rate $\lambda$ and can be either continued as stable jobs or destroyed at a cost $f$.

$$
r \Pi^{s}(x, e)=x+y(e)-w^{s}(x, e)+\lambda\left[\int \max \left\{\Pi^{s}\left(x^{\prime}, e\right), \Pi^{v}-f\right\} \mathrm{d} G\left(x^{\prime}\right)-\Pi^{s}(x, e)\right]
$$

Stable jobs filled with a worker whose education level is $e$ have a productivity $x+y(e)$, and pay a wage $w^{s}(x, e)$. With probability $\lambda$ they are hit by a productivity shock and can be either continued or destroyed at a cost $f$.

In a similar spirit, we can define the workers' asset values as follows:

$$
r W^{u}=\mu(\theta)\left[p \max \left\{W^{u}, W^{t}\left(x_{0}, e\right)\right\}+(1-p) \max \left\{W^{u}, W^{n s}\left(x_{0}, e\right)\right\}-W^{u}\right]
$$

For the sake of simplicity, utility from leisure and unemployment benefits are not considered here. A job seeker can meet a firm at rate $\mu(\theta)$. She is proposed a temporary job at rate $p$, while she can be hired on a new stable job at rate $1-p$. In either of the two cases, the value of the match-specific productivity always starts at $x=x_{0}$ for both types of jobs.

$$
r W^{n s}(x, e)=w^{n s}(x, e)+\lambda\left[\int \max \left\{W^{s}\left(x^{\prime}, e\right), W^{u}\right\} \mathrm{d} G\left(x^{\prime}\right)-W^{n s}(x, e)\right]
$$




$$
\begin{gathered}
r W^{s}(x, e)=w^{s}(x, e)+\lambda\left[\int \max \left\{W^{s}\left(x^{\prime}, e\right), W^{u}\right\} \mathrm{d} G\left(x^{\prime}\right)-W^{s}(x, e)\right] \\
r W^{t}\left(x_{0}, e\right)=w^{t}\left(x_{0}, e\right)+\lambda\left[\int \max \left\{W^{n s}\left(x^{\prime}, e\right), W^{u}\right\} \mathrm{d} G\left(x^{\prime}\right)-W^{t}\left(x_{0}, e\right)\right]
\end{gathered}
$$

A worker with education $e$ employed on a type $j=t, n s, s$ contract is paid a wage $w^{j}$. At rate $\lambda$, temporary or new stable jobs are hit by a productivity shock and are either terminated or become (new) stable jobs. Similarly, stable job are hit by productivity shocks at rate $\lambda$ and can be either terminated or continued.

\subsection{Decision rules in the decentralized economy}

Destruction thresholds. Let $x_{n s}$ denote the threshold below which temporary job are not converted into (new) stable jobs. Similarly let $x_{s}$ denote the firing thresholds for both stable and new stable jobs. Those thresholds can be defined as follows:

$$
\begin{gathered}
\Pi^{s}\left(x_{s}\right)=-f \Leftrightarrow \Omega^{s}\left(x_{s}\right)=0 \\
\Pi^{n s}\left(x_{n s}\right)=0 \Leftrightarrow \Omega^{n s}\left(x_{n s}\right)=0
\end{gathered}
$$

Free entry. Job creation is driven by free entry, which implies that firms enter the search market until the exhaustion of all rents. This implies

$$
\Pi^{v}=0
$$

Education Choices. A new born individual chooses her education level $e$ so as to maximize her expected utility $W^{u}(e)$ net of schooling $\operatorname{costs} c(e)$ :

$$
\max _{e \geq 0}<W^{u}(e)-c(e)>
$$

\subsection{Flows}

Let $G\left(x_{i}\right)$ and $\bar{G}\left(x_{i}\right) \equiv 1-G\left(x_{i}\right), \forall i=s, n s$, denote the cumulative distribution and the survival functions respectively. In addition, let us denote by $T, N, S$ and $U$ the mass numbers of temporary, new stable, stable and unemployed workers respectively. Labour market flows are depicted on figure 3 .

At any point in time, $\delta$ workers are born and immediately enter the labour market after the education stage. At the same time, the population faces a constant risk of dying $\delta$ irrespective of the employment status. A worker meets a firm on average at Poisson rate $\mu(\theta)$. As already mentioned, firms are only granted to hire a proportion $p$ of their workforce on a short-term basis, due to legal restrictions. Accordingly, the remaining proportion, $1-p$, is hired on a long-term basis. Long-term jobs (stable or new stable jobs) are destroyed at Poisson rate, $\lambda G\left(x_{s}\right)$, while short-term jobs (temporary jobs) are destroyed at Poisson rate, $\lambda G\left(x_{n s}\right)$. It is shown in the next section that $x_{n s} \geq x_{s}$, hence ensuring a higher destruction rate for temporary jobs whenever 


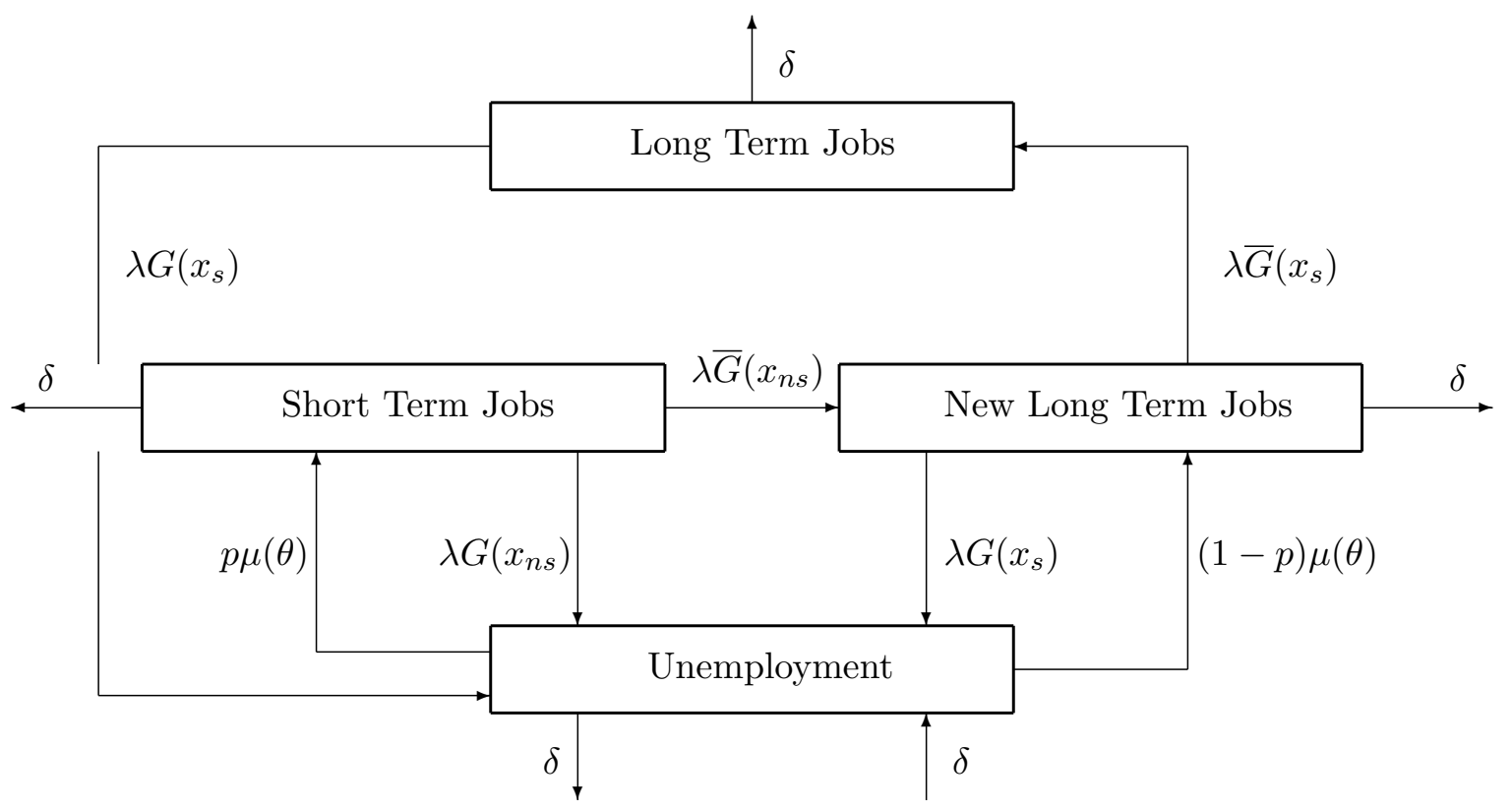

Figure 3: Labor Market Flows

$f>0$. Finally, temporary jobs are converted into stable jobs at Poisson rate $\lambda \bar{G}\left(x_{n s}\right)$. In a steady state, flows are summarized by the following equations:

$$
\begin{gathered}
\underbrace{(\delta+\mu(\theta)) U}_{\text {unemployment outflow }}=\underbrace{\delta+\lambda\left[G\left(x_{n s}\right) T+G\left(x_{s}\right) N+G\left(x_{s}\right) S\right]}_{\text {unemployment inflow }} \\
\underbrace{[\delta+\lambda] T}_{\text {temporary employment outflow }}=\underbrace{p \mu(\theta) U}_{\text {temporary employment inflow }} \\
\underbrace{(\delta+\lambda) N}_{\text {new stable jobs outflow }}=\underbrace{\mu(\theta)(1-p) U+\lambda \bar{G}\left(x_{n s}\right) T}_{\text {new stable jobs inflow }} \\
\underbrace{\left(\delta+\lambda G\left(x_{s}\right)\right) S}_{\text {stable jobs outflowstable jobs inflow }}=\underbrace{\lambda \bar{G}\left(x_{s}\right) N}
\end{gathered}
$$

After some algebra, we get:

$$
U=\frac{\delta+\lambda G\left(x_{s}\right)}{\delta+\lambda G\left(x_{s}\right)+\mu(\theta)\left[1-p \frac{\lambda G\left(x_{n s}\right)}{\delta+\lambda}+p \frac{\lambda G\left(x_{s}\right)}{\delta+\lambda}\right]}
$$

From this expression, we see that unemployment is increasing in the job destruction rates $\lambda G\left(x_{s}\right)$ and $\lambda G\left(x_{n s}\right)$ for the various types of jobs and a decreasing function of the exit rates from unemployment $\mu(\theta)$. Finally, when $p=0$, we get the familiar expression $U=\frac{\delta+\lambda G\left(x_{s}\right)}{\delta+\lambda G\left(x_{s}\right)+\mu(\theta)}$.

\section{$5 \quad$ Partial Equilibrium of the labour market}

\subsection{Productivity thresholds}

Using expressions (1) and (2) for the surpluses as well as the above definitions for thresholds, we get the following expressions for the endogeneous variables $x_{s}$ and $x_{n s}$ (see appendix for more 
details):

(i) hiring threshold for new stable jobs/destruction threshold for temporary jobs

$$
0=y(e)+x_{n s}+\frac{\lambda}{r+\lambda} \int_{x_{s}}^{x_{u}}\left(x^{\prime}-x_{s}\right) \mathrm{d} G\left(x^{\prime}\right)-r W^{u}-\lambda f
$$

(ii) destruction threshold for new stable and stable jobs

$$
0=y(e)+x_{s}+\frac{\lambda}{r+\lambda} \int_{x_{s}}^{x_{u}}\left(x^{\prime}-x_{s}\right) \mathrm{d} G\left(x^{\prime}\right)-r W^{u}+r f
$$

From these expressions, it is straightforward to obtain ${ }^{11}$

$$
x_{n s}=x_{s}+(r+\lambda) f
$$

As a result, firms are more demanding for newly created jobs than for stable jobs, and set a higher reservation productivity for the former than for the latter.

In the appendix, we show that $r W^{u}$ writes:

$$
r W^{u}=\frac{\beta \mu(\theta)}{r+\lambda+\beta \mu(\theta)}\left[\begin{array}{c}
x_{0}+y(e)+\frac{\lambda p}{r+\lambda} \int_{x_{n s}}^{x_{u}}\left(x^{\prime}-x_{n s}\right) \mathrm{d} G\left(x^{\prime}\right) \\
+\frac{\lambda(1-p)}{r+\lambda} \int_{x_{s}}^{x_{u}}\left(x^{\prime}-x_{s}\right) \mathrm{d} G\left(x^{\prime}\right)-\lambda(1-p) f
\end{array}\right]
$$

which implies that (25) can be rewritten, after some algebra and integration by part, as:

$$
\begin{aligned}
0= & x_{s}(r+\beta \mu(\theta))+y(e)(r+\lambda)-\beta \mu(\theta) x_{0}+\lambda x_{u}+(r+\lambda)(r+\beta \mu(\theta)) f \\
& +\frac{\lambda \beta \mu(\theta) p}{r+\lambda} \int_{x_{s}+(r+\lambda) f}^{x_{u}} G(x) \mathrm{d} x-\frac{\lambda(r+\lambda+\beta \mu(\theta) p)}{r+\lambda} \int_{x_{s}}^{x_{u}} G(x) \mathrm{d} x
\end{aligned}
$$

From the latter expression, the comparative statics properties of the productivity thresholds can then be summarized as follows:

$$
\begin{array}{cccccc} 
& e & \beta & \theta & f & p \\
x_{s} & (-) & (+) & (+) & (-) & (+) \\
x_{n s} & (-) & (+) & (+) & (+) & (+)
\end{array}
$$

COMPARATIVE STATICS PROPERTIES OF PRODUCTIVITY THRESHOLDS

The above table highlights a few properties, some of which will be crucial for our analysis of the benefits from education. In particular, the two productivity thresholds decrease with a worker's productivity. Given that productivity increases with education, one should conclude that the higher a worker's education, the lower the reservation product. This is consistent with the fact that higher educated workers benefit from better job stability and when hired on a temporary contract, their jobs are more likely to be converted into permanent jobs.

In addition, both thresholds increase with tightness $\theta$ and with the approval rate of temporary jobs $p$. A worker's outside options $W^{u}$ increases with those variables, which reduces the surplus

\footnotetext{
${ }^{11}$ Note that the former expressions are established under the assumption that all thresholds corresponds to 'interior solutions' i.e. we shall restrict our attention to equilibrium configurations where both $x^{n s}$ and $x^{s} \in\left[x_{l}, x_{u}\right]$.
} 
to be shared, and makes both firms and workers more willing to dissolve a match. Similarly, an increase in worker's bargaining power makes jobs less profitable and fosters jobs' destruction.

The firing threshold $x_{s}$ decreases with firing costs. Firing costs reduce the option value of terminating a stable job and this fosters labour hoarding, which is the very purpose of firing restrictions. But at the same time, firms become more reluctant to transform temporary jobs into permanent contracts and $x_{n s}$ increases with firing costs. Employers anticipate that in the event of an adverse productivity shock, they will have to bear larger firing costs once the worker is hired on a stable job, which makes them less willing to transform temporary jobs into permanent jobs. As a result, firing costs do not necessarily improve job stability given the opposite effects on the productivity thresholds for temporary and permanent contracts.

The next section investigates the impact of such a distortion on the return to schooling.

\subsection{Educational choices}

We here characterize the partial equilibrium properties of the return to education. A new born individual chooses $e$ so as to maximize

$$
\max _{e \geq 0}<W^{u}(e)-c(e)>
$$

Using (27) and taking into account that $x_{n s} \equiv x_{n s}(e)$ and $x_{s} \equiv x_{s}(e)$ according to (26) and (28), the first order condition to (29) writes down:

$$
\frac{\beta \mu(\theta)}{r(r+\lambda+\beta \mu(\theta))}\{\underbrace{y^{\prime}(\widehat{e})}_{\text {direct wage return }}-\underbrace{\frac{\lambda p \bar{G}\left(x_{n s}\right)}{r+\lambda} x_{n s}^{\prime}(\widehat{e})-\frac{\lambda(1-p) \bar{G}\left(x_{s}\right)}{r+\lambda} x_{s}^{\prime}(\widehat{e})}_{\text {return to job stability }}\}=\underbrace{c^{\prime}(\widehat{e})}_{\text {marginal cost }}
$$

The optimal educational level $\widehat{e}$ equalizes marginal benefit $d W^{u} / d e$ on the LHS and marginal cost from education, on the RHS of (30). The marginal benefit from education deserves some special attention, as the return to schooling is made up of three terms: (i) education raises productivity and wages through rent sharing, which gives rise to a direct wage return to schooling, but in addition, education also makes the employment relationships more stable; (ii) the more productive the temporary jobs, the more easily they are transformed into stable jobs $\left(x_{n s}^{\prime}(e) \leq\right.$ 0 ), i.e. the higher the conversion rate; (iii) the more productive the stable jobs, the less easily they are destroyed $\left(x_{s}^{\prime}(e) \leq 0\right)$. The second and third effects correspond to a a return to job stability. Those effects are broadly in line with the stylized facts which suggest that more educated workers are more productive, earn more, face better job stability and benefit from higher conversion rates when hired on a temporary contract ${ }^{12}$.

As the following expression shows, it turns out that the latter type of return is also an indirect wage return, in the sense that more job stability leads to a higher rate of use of human

\footnotetext{
${ }^{12}$ Namely, (30) generalizes to the case of heterogeneous workers. For instance, if workers had different marginal costs of education, we would get: $\frac{\beta \mu(\theta)}{r(r+\lambda+\beta \mu(\theta))}\left\{y^{\prime}\left(\widehat{e}_{i}\right)-\frac{\lambda p \bar{G}\left(x_{n s_{i}}\right)}{r+\lambda} x_{n s_{i}}^{\prime}\left(\widehat{e_{i}}\right)-\frac{\lambda(1-p) \bar{G}\left(x_{s_{i}}\right)}{r+\lambda} x_{s_{i}}^{\prime}\left(\widehat{e_{i}}\right)\right\}=c_{i}^{\prime}\left(\widehat{e_{i}}\right)$ for type-i workers.
} 
capital, as a worker's human capital will remain idle for a shorter proportion of the time when jobs become more stable. Namely, using (26) and (28), we get:

$$
x_{n s}^{\prime}(e)=x_{s}^{\prime}(e)=\frac{-(r+\lambda) y^{\prime}(e)}{r+\lambda G\left(x_{s}\right)\left(1+\frac{p \beta \mu(\theta)}{r+\lambda}\right)+\beta \mu(\theta)\left(1-p \frac{\lambda G\left(x_{n s}\right)}{r+\lambda}\right)}
$$

Inserting this expression in (30), the return to schooling $R=d W^{u} / d e$ can be then rewritten ${ }^{13}$ :

$$
R=\frac{\beta \mu(\theta)}{r+\lambda+\beta \mu(\theta)} \frac{y^{\prime}(\widehat{e})}{r}[\underbrace{1}_{\text {direct wage return }}+\underbrace{\frac{\lambda\left[p \bar{G}\left(x_{n s}\right)+(1-p) \bar{G}\left(x_{s}\right)\right]}{r+\lambda G\left(x_{s}\right)\left(1+\frac{p \beta \mu(\theta)}{r+\lambda}\right)+\beta \mu(\theta)\left(1-p \frac{\lambda G\left(x_{n s}\right)}{r+\lambda}\right)}}_{\text {indirect wage return }}]
$$

where $\bar{G}(x)=1-G(x)$. As will be made clear below, this expression of the return to schooling generalizes that previously obtained in e.g. Laing, Palivos and Wang (1995) or Burdett and Smith (2002) in models with search frictions but without endogeneous job destruction.

The term into brackets can be decomposed in two parts, corresponding respectively to the direct and indirect wage return to schooling. Two remarks are in order.

First, it is worth noting that (32) generalizes the expression of the return to human capital to the case of a frictional economy with endogeneous job creation/destruction and heterogeneous labour contracts. In the limit case where search frictions die down, the exit rate from unemployment $\mu(\theta)$ tends to infinity, which raises workers' outside options to the point where they are paid their marginal product. This implies that

$$
\lim _{\theta \rightarrow+\infty} R=y^{\prime}(\widehat{e}) / r
$$

In this case, the return to schooling $R$ tends to $\frac{y^{\prime}(e)}{r}$, which corresponds to the standard expression of the return to human capital in a frictionless labour market, such as the one studied in Becker (1964).

Second, note that in the special case of a frictional economy with no heterogeneity in labour contracts $(p=0)$, the return to human capital simplifies to:

$$
R=\frac{\beta \mu(\theta)}{r+\lambda G\left(x_{s}\right)+\beta \mu(\theta)} \frac{y^{\prime}(\widehat{e})}{r}
$$

which looks more like the expression studied in e.g. Laing et al. (1995), except that it is here extended to a setting with endogeneous job destruction. Henceforth, the partial equilibrium properties of the return to schooling can be derived in the more general case where $p \geq 0$, which is the case depicted by (32). From (32), first note that $R$ decreases with the two productivity thresholds $x_{n s}$ and $x_{s}$. Which means that job stability is beneficial to the return to education, as more frequent job terminations implies that the worker's human capital remains idle for a

\footnotetext{
${ }^{13}$ Note that the second order condition requires $d^{2} W^{u} / d e^{2}=d R / d e \leq 0$.
} 
larger proportion of the time. This enables us to establish that the effect of firing costs on the incentives to schooling are as follows:

$$
\frac{d R}{d f}=\overbrace{\frac{\partial R}{\partial x_{n s}} \frac{d x_{n s}}{d f}}^{\text {temporary job effect }}+\overbrace{\frac{\partial R}{\partial x_{s}} \frac{d x_{s}}{d f}}^{\text {stable job effect }}
$$

Firing costs raise the thresholds $x_{n s}$ and decrease the firing threshold $x_{s}$. This gives rise to two opposite effects: (i) the first one is detrimental to the return to schooling given that temporary jobs will be less frequently transformed into new stable jobs as firing costs increase which implies that as firing costs increase, it becomes more likely that a worker's human capital investment remains idle for a large fraction of the time, which is detrimental to the return to education; (ii) but at the same time, job stability is beneficial to human capital investments ${ }^{14}$. As firing costs increase, fewer stable jobs are destroyed and this raises the incentives to schooling. Therefore the global effect is ambiguous. As a more direct calculation shows, the sign of $\frac{d R}{d f}$ is the same as that of:

$$
\begin{aligned}
& -\lambda p g\left(x_{n s}\right) \frac{d x_{n s}}{d f}\left[r+\lambda G\left(x_{s}\right)+\beta \mu(\theta)+\frac{\beta \mu(\theta) \lambda \bar{G}\left(x_{s}\right)}{r+\lambda}\right] \\
& -\lambda g\left(x_{s}\right) \frac{d x_{s}}{d f}\left[(1-p)\left(r+\lambda G\left(x_{s}\right)+\beta \mu(\theta)\right)+\frac{\beta \mu(\theta) \lambda p \bar{G}\left(x_{n s}\right)}{r+\lambda}\right]
\end{aligned}
$$

which is ambiguous given that each member depends on the value of the density function $g($. which can take any value at a given point in the general case. Hence, a rise in firing costs can thus raise the return to schooling, though this is a local result.

Considering now the effect of the approval rate of temporary jobs, we see from (30) that, at given tightness, the effect of STJ on the return to schooling is unambiguously negative:

$$
\frac{d R}{d p}=\overbrace{\frac{\partial R}{\partial p}}^{\text {direct effect }}+\overbrace{\frac{\partial R}{\partial x_{n s}} \frac{d x_{n s}}{d p}}^{\text {temporary job effect }}+\overbrace{\frac{\partial R}{\partial x_{s}} \frac{d x_{s}}{d p}}^{\text {stable job effect }} \leq 0
$$

Namely, we have $\frac{\partial R}{\partial p}=\frac{\beta \mu(\theta)}{r+\lambda+\beta \mu(\theta)} \frac{y^{\prime}(e)}{r} \frac{\left[\lambda G\left(x_{s}\right)-\lambda G\left(x_{n s}\right)\right]\left[r+\lambda G\left(x_{s}\right)\right]\left[1+\frac{\beta \mu(\theta)}{r+\lambda}\right]}{\left[r+\lambda G\left(x_{s}\right)\left(1+\frac{p \beta \mu(\theta)}{r+\lambda}\right)+\beta \mu(\theta)\left(1-p \frac{\lambda G\left(x_{n s}\right)}{r+\lambda}\right)\right]^{2}} \leq 0$ given that $x_{n s} \geq x_{s}$, while the sign of $\frac{\partial R}{\partial x_{n s}} \frac{d x_{n s}}{d p}+\frac{\partial R}{\partial x_{s}} \frac{d x_{s}}{d p}$ is obvious from the above analysis. The interpretation is the following: a rise in the proportion of STJ tends to depress the return to schooling as this implies that on average, workers will experience more frequent unemployment spells. This is so for two main reasons: First, temporary jobs are more likely to be destroyed, and job instability is detrimental to the return to schooling. Second, both destruction thresholds increase with $p$, which further depresses the return to schooling.

Still, those are partial equilibrium results in the sense that tightness $\theta$ and contact rates $\mu(\theta)$ are held constant. It should be noted however that the return to schooling depends both directly

\footnotetext{
${ }^{14}$ Note that we here assume that workers remain employable when firing costs increase. Otherwise the return to education $R$ is nil and the optimum is at a corner solution.
} 
on $\theta$ via the worker's contact rate $\mu(\theta)$ and indirectly, given the dependence of the hiring and firing thresholds vis-à-vis $\theta$, as can be deduced from (26) and (28). We get

$$
\frac{d R}{d \theta}=\overbrace{\substack{\partial \theta \\+}}^{\text {direct job creation effect }}+\overbrace{\underbrace{\frac{\partial R}{\partial x_{n s}} \frac{d x_{n s}}{d \theta}+\frac{\partial R}{\partial x_{s}} \frac{d x_{s}}{d \theta}}_{-}}^{\text {indirect job destruction effect }}
$$

It is noticeable that contrary to a model with an exogeneous job destruction rate, the return to schooling is not necessarily positively related to tightness: when tightness increases, workers exit faster from unemployment and their human capital remains idle for a shorter period of time. This is beneficial to human capital investments. However, when tightness raises, employment relationships become more unstable, which is detrimental to the return to schooling. Namely $\frac{\partial R}{\partial x_{n s}} \frac{d x_{n s}}{d \theta}+\frac{\partial R}{\partial x_{s}} \frac{d x_{s}}{d \theta}$ is of the same sign as:

$$
\begin{aligned}
& -\lambda g\left(x_{s}\right)\left[(1-p)\left(r+\lambda G\left(x_{s}\right)+\beta \mu(\theta)\right)+\beta \mu(\theta) p \frac{\lambda \bar{G}\left(x_{n s}\right)}{r+\lambda}\right] \\
& -\lambda p g\left(x_{n s}\right)\left[r+\lambda G\left(x_{s}\right)+\beta \mu(\theta)+\beta \mu(\theta) p \frac{\lambda \bar{G}\left(x_{n s}\right)}{r+\lambda}\right]
\end{aligned}
$$

which is negative. It can also be seen from these expressions that the quantitative importance of such a negative effect depends on the density function $g($.$) . As it can be arbitrarily high in$ the general case, we can conclude that in partial equilibrium, a rise in tightness could locally reduce the return to schooling.

We now turn to the general equilibrium analysis in the next section.

\section{Equilibrium analysis}

In this section, we characterize the equilibrium with endogeneous schooling, job creation and job destruction. We only consider symmetric equilibria where all workers choose the same education effort $e$. There is one variable left to determine, the so-called labour market tightness $\theta$ which results from the free entry condition $\Pi^{v}=0$, which closes the model. 
Definition An equilibrium with endogeneous schooling is a tuple $\left(\theta^{*}, x_{n s}^{*}, x_{s}^{*}, e^{*}, U^{*}\right)$ solving the following set of equations:

(i) Free entry

$$
\frac{\gamma}{\eta\left(\theta^{*}\right)}=\frac{1-\beta}{r+\lambda}\left[x_{0}-x_{s}^{*}-f(r+\lambda)-\frac{\lambda p}{r+\lambda} \int_{x_{n s}^{*}}^{x_{u}} G(x) \mathrm{d} x+\frac{\lambda p}{r+\lambda} \int_{x_{s}^{*}}^{x_{u}} G(x) \mathrm{d} x\right]
$$

(ii) Destruction threshold for stable jobs

$$
\begin{aligned}
0= & \left(r+\beta \mu\left(\theta^{*}\right)\right) f+y\left(e^{*}\right)-\frac{\beta \mu\left(\theta^{*}\right)}{r+\lambda} x_{0}+x_{s}^{*} \frac{r+\beta \mu\left(\theta^{*}\right)}{r+\lambda}+\frac{\lambda}{r+\lambda} x_{u} \\
& -\frac{\lambda\left[r+\lambda+p \beta \mu\left(\theta^{*}\right)\right]}{r+\lambda} \int_{x_{s}^{*}}^{x_{u}} \frac{G(x)}{r+\lambda} \mathrm{d} x+\frac{\lambda p \beta \mu\left(\theta^{*}\right)}{r+\lambda} \int_{x_{s}^{*}+(r+\lambda) f}^{x_{u}} \frac{G(x)}{r+\lambda} \mathrm{d} x
\end{aligned}
$$

(iii) Destruction threshold for temporary jobs

$$
x_{n s}^{*}=x_{s}^{*}+(r+\lambda) f
$$

(iv) Education Effort

$$
\frac{\beta \mu\left(\theta^{*}\right)}{r+\lambda+\beta \mu\left(\theta^{*}\right)} \frac{y^{\prime}\left(e^{*}\right)}{r}\left[1+\frac{\lambda\left[p\left(1-G\left(x_{n s}^{*}\right)\right)+(1-p)\left(1-G\left(x_{s}^{*}\right)\right)\right]}{r+\lambda G\left(x_{s}^{*}\right)\left(1+\frac{p \beta \mu\left(\theta^{*}\right)}{r+\lambda}\right)+\beta \mu\left(\theta^{*}\right)\left(1-p \frac{\lambda G\left(x_{n s}^{*}\right)}{r+\lambda}\right)}\right]=c^{\prime}\left(e^{*}\right)
$$

(v) Flow equilibrium

$$
U^{*}=\frac{\delta+\lambda G\left(x_{s}^{*}\right)}{\delta+\lambda G\left(x_{s}^{*}\right)+\mu\left(\theta^{*}\right)\left[1-p \frac{\lambda G\left(x_{n s}^{*}\right)}{\delta+\lambda}+p \frac{\lambda G\left(x_{s}^{*}\right)}{\delta+\lambda}\right]}
$$

The equilibrium can be determined as follows. Given that $x_{n s}^{*}=x_{s}^{*}+(r+\lambda) f$, the free entry condition can be rewritten

$$
\frac{\gamma}{\eta\left(\theta^{*}\right)}=\frac{1-\beta}{r+\lambda}\left[x_{0}-x_{s}^{*}-(r+\lambda) f-\frac{\lambda p}{r+\lambda} \int_{x_{s}^{*}+(r+\lambda) f}^{x_{u}} G(x) \mathrm{d} x+\frac{\lambda p}{r+\lambda} \int_{x_{s}^{*}}^{x_{u}} G(x) \mathrm{d} x\right]
$$

which defines implicitly $x_{s}^{*} \equiv x_{s}\left(\theta^{*}\right)$, a decreasing function of tightness. Reporting in (39) and (41) we have

$$
\begin{aligned}
0= & y\left(e^{*}\right)-\frac{\beta \mu\left(\theta^{*}\right)}{r+\lambda} x_{0}+x_{s}^{*}\left(\theta^{*}\right) \frac{r+\beta \mu\left(\theta^{*}\right)}{r+\lambda}+\frac{\lambda}{r+\lambda} x_{u}+\left(r+\beta \mu\left(\theta^{*}\right)\right) f \\
& -\frac{r+\lambda+\beta p \mu\left(\theta^{*}\right)}{r+\lambda} \int_{x_{s}^{*}\left(\theta^{*}\right)}^{x_{u}} \frac{\lambda}{r+\lambda} G(x) \mathrm{d} x+\frac{p \beta \mu\left(\theta^{*}\right)}{r+\lambda} \int_{x_{s}^{*}\left(\theta^{*}\right)+(r+\lambda) f}^{x_{u}} \frac{\lambda}{r+\lambda} G(x) \mathrm{d} x
\end{aligned}
$$

and

$$
\begin{aligned}
& \frac{\beta \mu\left(\theta^{*}\right)}{r+\lambda+\beta \mu\left(\theta^{*}\right)} \frac{y^{\prime}\left(e^{*}\right)}{r}\left[1+\frac{\lambda\left[p\left(1-G\left(x_{s}\left(\theta^{*}\right)+(r+\lambda) f\right)\right)+(1-p)\left(1-G\left(x_{s}^{*}\left(\theta^{*}\right)\right)\right)\right]}{r+\lambda G\left(x_{s}^{*}\left(\theta^{*}\right)\right)\left(1+\frac{p \beta \mu\left(\theta^{*}\right)}{r+\lambda}\right)+\beta \mu\left(\theta^{*}\right)\left(1-p \frac{\lambda G\left(x_{s}\left(\theta^{*}\right)+(r+\lambda) f\right)}{r+\lambda}\right)}\right] \\
= & c^{\prime}\left(e^{*}\right)
\end{aligned}
$$


Equation (44) can be interpreted as a labour demand (LD) curve as it describes how tightness reacts to a change in education. Along this curve, a rise in education improves workers' productivity, which gives firms more incentives to advertise vacancies due to higher expected profits. In turn, equation (45) defines an optimal schooling (OS) locus. Along this locus, a rise in job creation implies that workers will exit faster from unemployment, raising the return to their educational investment. For those reasons, equations (44) and (45) define two increasing relationships between education and tightness. Solving for an equilibrium $\left(e^{*}, \theta^{*}\right)$ then boils down to determining a fixed point of the system formed by equations (44) and (45). Given the equilibrium values of $\left(e^{*}, \theta^{*}\right)$ and using (43) which defines $x_{s}^{*}$ as a function of $\theta^{*}$, we can then deduce $x_{n s}^{*}=x_{s}^{*}+(r+\lambda) f$ and the equilibrium unemployment rate results from the expression of $U^{*}$. Then, equilibrium proportions of the various types of jobs follow.

The labour market equilibrium is represented below on Figure 5 in the case where an equilibrium exists and is unique. Such a case may prevail if firing costs are sufficiently low. However, existence and uniqueness are not granted for larger firing costs. This is formally stated in the following proposition.

\section{Existence, uniqueness, multiplicity}

Proposition: Let us define $\frac{\lambda}{r+\lambda} \int_{x_{s}(\theta)}^{x_{u}} G(x) \mathrm{d} x-\frac{\lambda}{r+\lambda} x_{u}-r f-\frac{r}{r+\lambda} x_{s}(\theta)=\underline{y}(\theta)$. There exists a unique equilibrium whenever $\underline{y}(0) \leq 0$. When $\underline{y}(0)>0$ either there is no equilibrium, or there can be more than one equilibrium.

Proof. see Appendix.

Inspection of equation (44) reveals that its intercept can be negative (positive) with small (large) firing costs. When firing costs are small, a unique equilibrium may prevail, as is depicted on figure 5. However, when firing costs are large, two different cases may arise : (i) either the (LD) and (OS) curves do not intersect at all, or (ii) they may cross more than once, i.e. a low-skill trap can take place.

(i) EPL creates some rigidities which imply the existence of a minimum level of productivity $\underline{y}$ below which matches may turn out to be unprofitable for firms. In turn, when employment prospects are nil, it is not worth investing in education, and the equilibrium is a corner solution where nobody invests in human capital while no firm advertises vacancies. When the economy is at the corner solution, it may be quite difficult to escape from such a situation, given that a small increase in the education level may have no impact on the equilibrium outcome, and will only move the economy toward an inner equilibrium provided that productivity becomes larger than a threshold level above which matches become profitable for firms. Otherwise the economy will remain at the corner solution.

(ii) This is not the only potential outcome, and there may be more than one equilibrium. Multiple equilibria result from the positive interactions (strategic complementarities) between job creation and educational investments, and as a result, the economy may be stuck in a low-skill trap. This is a common result in matching models with education efforts such as (among others) 
Laing et al (1995), or Burdett and Smith (2002) where multiple equilibria are also highlighted in settings without job destruction ${ }^{15}$. Perhaps more interestingly, it appears that a low-skill trap may also be attributed to a high level of firing costs. Figure 4 depicts a simple case where this is the case.

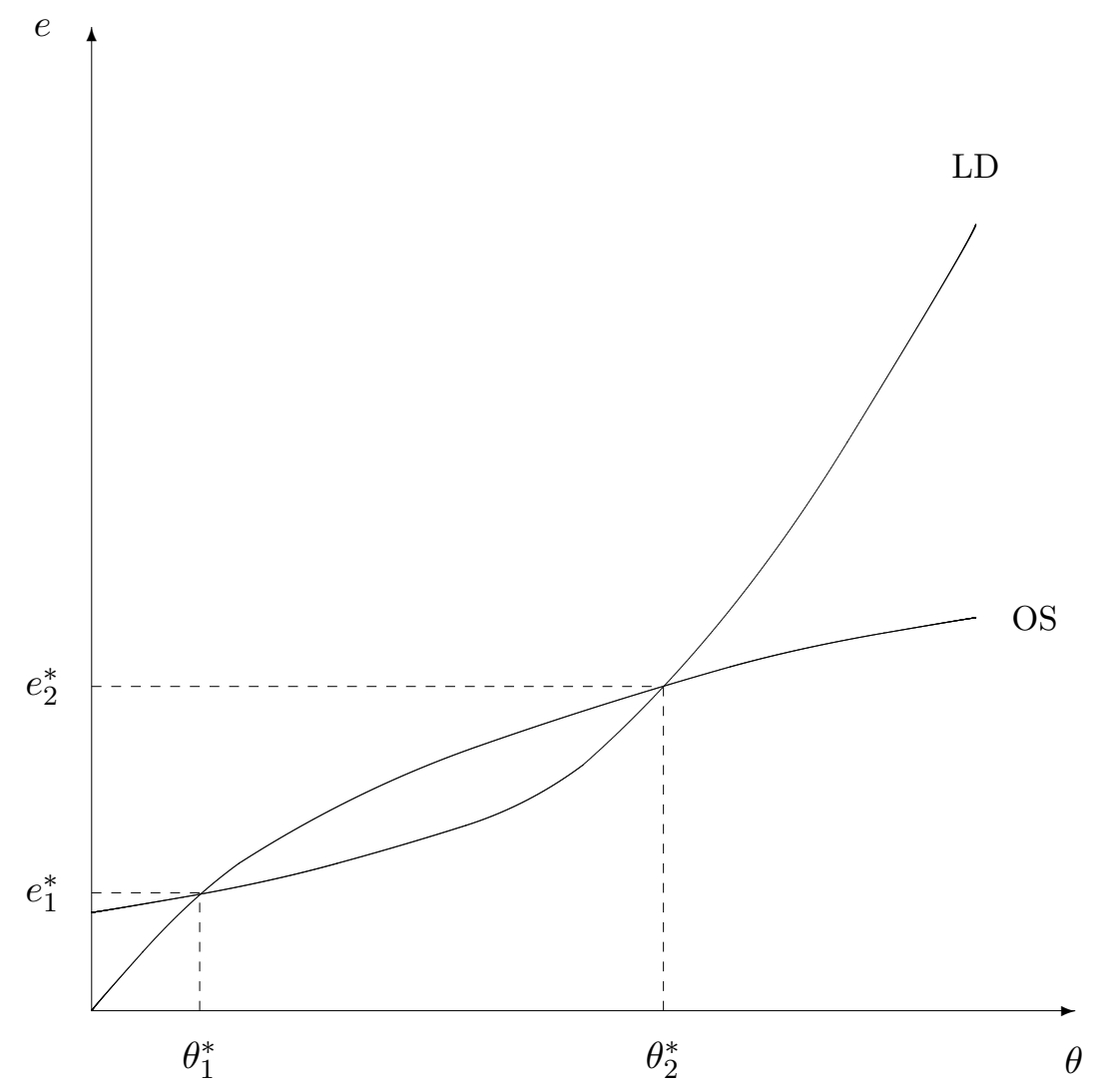

Figure 4: A low-skill trap. The equilibrium values of the labor market tightness and the education level are determined by the intercepts of the (LD) and (OS) curves.

In the case depicted here, there are three equilibria: the corner solution where nobody invests in education and no vacancy is advertised, and two inner equilibria, with high (low) educational investments/high (low) job creation, while job destruction is not necessarily high (low) when job creation is high (low) given that job stability improves with educational investments. Compared with the previous contributions where a low-skill trap was also highlighted, a noticeable property is here that the trap may result from high firing costs. Namely, this is more likely to occur when firing costs are large, given that the (LD) curve moves up with firing costs $f$. On the contrary, the trap becomes less likely when the approval rate of temporary jobs $p$ increases, as the (LD) curve moves down with the approval rate $p$. Thus firing costs (the approval rate) make a low-

\footnotetext{
${ }^{15}$ See also Snower (1996) or Saint-Paul (1996) where multiple equilibria are obtained in dual matching models.
} 
skill trap more (less) likely ${ }^{16}$. Note also that among these equilibria depicted on figure 4 , one is unstable, so that only the "high" equilibrium $\left(\theta_{2}^{*}, e_{2}^{*}\right)$ and the corner solution are relevant. We hereafter choose to concentrate on the positive and normative properties of the equilibrium, keeping in mind that a corner solution is always a possible outcome.

When firing costs are not too large, the equilibrium is unique and some comparative statics can be performed. Namely, it can be shown that the LD curve moves up with firing costs $f$ and down with the approval rate of temporary jobs $p$ due to negative (positive) effect of firing costs (approval rate) on job creation while the OS curve moves up with firing costs and down with the approval rate, due to the positive (negative) effect of firing costs on education investments.

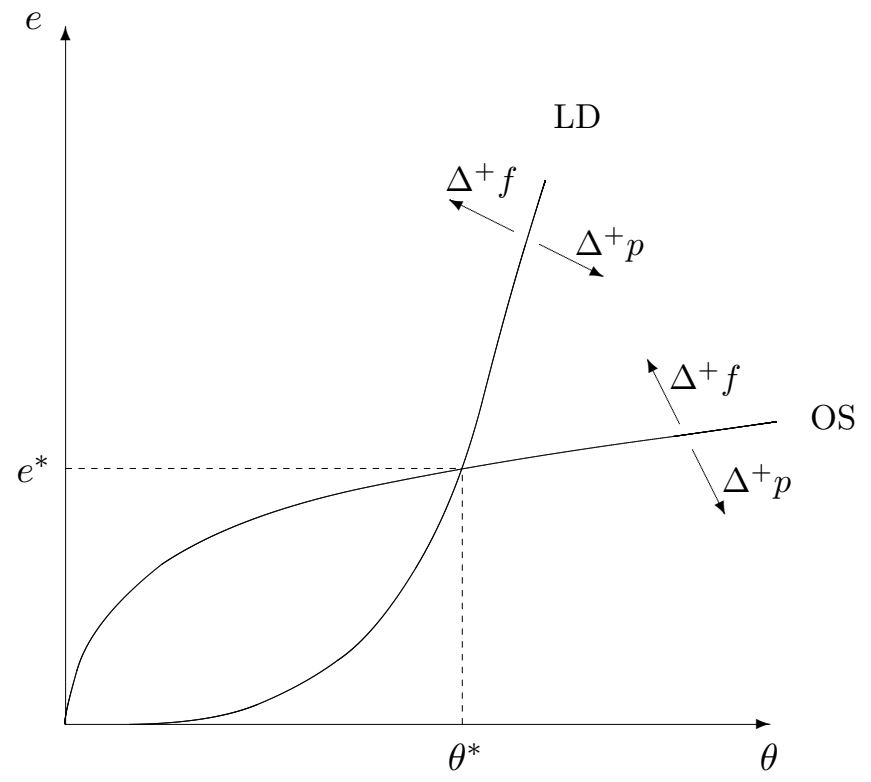

Figure 5: Unique equilibrium and comparative statics properties. The equilibrium values of the labor market tightness and the education level are determined of the (LD) and (OS) curves. Directional arrows indicate how the curves moves following an increase in the firing costs $f$ or in the approval rate $p$.

It turns out that in equilibrium, the two features of EPL have an ambiguous effect on tightness and education investments, given the above depicted moves of the two curves.

For instance, a rise in firing costs $f$ may well increase education, depending on a combination of job creation and job destruction effects as can be intuitively inferred from the results presented in Section 5.2:

$$
\frac{d e^{*}}{d f}=\underbrace{\overbrace{\frac{\partial e^{*}}{\partial x_{n s}} \frac{d x_{n s}^{*}}{d f}+\frac{\partial e^{*}}{\partial x_{s}} \frac{d x_{s}^{*}}{d f}}^{\text {job destruction effect }}+\overbrace{\frac{\partial e^{*}}{\partial \theta} \frac{d \theta^{*}}{d f}}^{\text {job creation effect }}}_{+/-}
$$

\footnotetext{
${ }^{16}$ It can be shown that $\underline{y}$ the intercept of the (LD) curve moves up with $f$ and down with $p$, see Appendix.
} 
which turn out to be globally ambiguous. Tightness may also increase or decrease with $f$, as the rise in labour market rigidity may dominate the beneficial effect on education $e^{*}$ and productivity $y\left(e^{*}\right)$. Namely, we have:

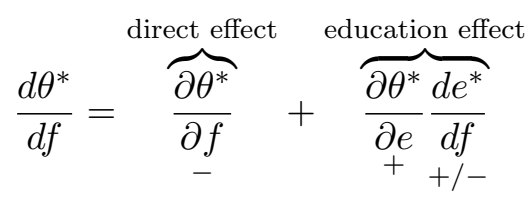

Otherwise stated, we see from the latter expression that a rise in firing costs involves an additional effect on tightness compared to a model with exogeneous education, which may sometimes reduce the negative effect of labour market rigidities on tightness or even dominate in some cases. This is the case, if the shift in the (OS) curve is sufficiently large compared with the shift in the (LD) curve. In the next section, we provide a quantitative evaluation of those effects.

Similarly, a rise in the approval rate $p$ is likely to decrease the equilibrium education level $e^{*}$, depending on a combination of job creation and job destruction effects which is ambiguous:

$$
\frac{d e^{*}}{d p}=\underbrace{\frac{\partial e^{*}}{\partial p}+\overbrace{\frac{\partial e^{*}}{\partial x_{n s}} \frac{d x_{n s}^{*}}{d p}+\frac{\partial e^{*}}{\partial x_{s}} \frac{d x_{s}^{*}}{d p}}^{\text {job destruction effect }}+\overbrace{\frac{\partial e^{*}}{\partial \theta} \frac{d \theta^{*}}{d p}}^{\text {job creation effect }}}_{+/-}
$$

A rise in the approval rate of temporary contracts involves a direct beneficial effect on job creation, but may also reduce the incentives to schooling which would imply a negative effect education effect on tightness:

$$
\frac{d \theta^{*}}{d p}=\overbrace{\frac{\partial \theta^{*}}{\partial p}}^{\text {direct effect }}+\overbrace{\frac{\partial \theta^{*}}{\partial e} \frac{d e^{*}}{d p}}^{\text {education effect }}+\underset{+/-}{+}
$$

It is worth noting that the latter education effect is specific to our framework, and implies that the effect of $p$ on tightness can sometimes be magnified, reduced or even reversed compared to a model where the education level is kept exogeneous.

Given such ambiguities, it may be useful to proceed to some numerical exercises to quantify the potential importance of the various theoretical effects studied so far. This is the subject of the next section.

\section{A quantitative exercise}

In this section,we provide a very rough calibration of the model, aimed at evaluating the respective importance of the counteractive effects highlighted in the previous sections. Further, we have two additional motivations. The first one is rather theoretic. Given that most of the literature studies the impact of EPL at given education level, we aim at comparing the results obtained with endogeneous rather than exogeneous education. Our second aim is more applied. Dualism in labour contracts being often criticized as offsetting the potential beneficial effects 
of firing restrictions, if any (see e.g. Blanchard and Landier, 2002, Cahuc and Postel-Vinay, 2002), our aim is to evaluate how large the potentially beneficial effects of EPL on education can be in a European-style economy, characterized by a dual system with a pretty large share of temporary contracts.

\subsection{Parameter choices}

The period is the year and the discount rate, $r$, is set to $5 \%$. As is common in the matching literature, we adopt a CRS matching function of the form $m(U, V)=k U^{\alpha} V^{1-\alpha}$ (see e.g. Blanchard and Diamond, 1989 and Petrongolo and Pissarides, 2001) where $k$ is a mismatch parameter, $\alpha$ and $1-\alpha$ denote the elasticity of the matching function with respect to search inputs. In addition, we assume that workers bargaining power, $\beta$, is equal to $\alpha$ so that $\beta=\alpha=\frac{1}{2}$ as is standard in the literature. When education is exogeneous, this configuration is sufficient to guarantee constrained efficiency in the laissez-faire case where $p=f=0$. We also choose Cobb-Douglas technologies to relate education to productivity, i.e. $y(e)=a_{0} e^{a_{1}}$, as for the cost function $c(e)=c_{0} e^{c_{1}}$. We set parameter values to $a_{0}=0.35, a_{1}=0.5, c_{0}=0.25$ and $c_{1}=1.5$ so as to match reasonable values for the endogeneous variables. We also perform some robustness checks with respect to these parameters. The distribution of productivity shocks is assumed to be uniform over $[-1,1]$ that is the CDF writes down $G(x)=(x+1) / 2$. The match-specific component of every new match, $x_{0}$, is set equal to 0.3 . Finally, the values of the other parameters are then chosen so as to match a typical European economy with the following characteristics ${ }^{17}$ : (i) an unemployment rate of about 10\%; (ii) an average annual job destruction rate of $10 \%$ and (iii) an average unemployment duration close to one year. Parameter values and resulting endogeneous variables are summarized in the table below.

\begin{tabular}{|c|c|c|c|c|c|c|c|}
\hline \multirow[t]{4}{*}{ Parameters values } & $k$ & $\alpha$ & $\beta$ & $\lambda$ & $r$ & $\delta$ & $\gamma$ \\
\hline & 0.7 & 0.5 & 0.5 & 0.3 & 0.05 & 0.025 & 0.4 \\
\hline & $a_{0}$ & $a_{1}$ & $c_{0}$ & $c_{1}$ & $x_{l}$ & $x_{u}$ & $x_{0}$ \\
\hline & 0.35 & 0.5 & 0.25 & 1.5 & -1 & 1 & 0.3 \\
\hline Endogeneous variables & & \multicolumn{2}{|c|}{$\begin{array}{c}\text { Unemp. rate } \\
10.5 \%\end{array}$} & \multicolumn{2}{|c|}{$\begin{array}{c}\text { Job dest. rate } \\
10.3 \%\end{array}$} & \multicolumn{2}{|c|}{$\begin{array}{l}\text { Unemp. spell } \\
11 \text { months }\end{array}$} \\
\hline
\end{tabular}

BASELINE PARAMETER VALUES

We proceed to our numerical exercises in two steps: keeping the laissez faire equilibrium where $(p, f)=(0,0)$ as a benchmark, we let both policy parameters $f$ and $p$ vary from $(0,0)$ to $(1,1)$, and we depict the response of the key variables of the economy such as exit rate from unemployment, education attainment, short-term and long-term job destruction rates,

\footnotetext{
${ }^{17}$ In this perspective, our parameters are chosen with two criteria in mind: (i) the value of the parameters themselves have to be realistic and coherent with the values usually chosen in the literature; (ii) the values of the endogenous variable that follow from these parameters have to be reasonable.
} 
unemployment rate and share of temporary jobs in global employment to these shifts when education is endogeneous. In each case, we have also made a similar exercise when the level of education is kept exogeneous, so as to highlight the importance of endogeneous rather than exogeneous education on the key variables. When education is endogeneous, we have also carefully checked that the equilibrium is unique, i.e. that the (LD) and (OS) curves do not cross more than once for the parameter values considered here ${ }^{18}$.

\subsection{EPL, educational investment and unemployment}

Figure 6 depicts the effects of variations in firing costs $f$ and in the approval rate of temporary jobs $p$. It can be seen that while a rise in firing costs may reduce unemployment and encourage educational investments in any of the cases depicted, a rise in the approval rate of temporary jobs may increase unemployment and discourage education efforts.

[Figure 6 about here]

For education (panel b) as for unemployment (panel e), we can conclude that part if not all of the potentially beneficial effect of firing costs on job stability is offset by the rise in job instability due to temporary jobs, as they will be less easily transformed into new stable jobs when firing costs increase in this case. This can be seen from panel c, where the job destruction rate for temporary jobs increases with $f$ for any proportion of temporary jobs $p>0$. The higher $p$, the stronger this effect. Hence, the higher $p$ the lower the decrease in unemployment induced by firing costs, and the higher $p$, the higher unemployment.

It is also worth comparing these effects when education is endogeneous to what would have been obtained, had the education level remained constant. The effects of variations in $p$ and $f$ are depicted on Figure 7.

\section{[Figure 7 about here]}

From this figure, we see that for the parameter values we consider here, firing costs reduce unemployment by a larger amount when education is endogeneous, given that (i) the rise in education attainment partly offsets the negative effect of firing costs on job creation, and (ii) the rise in education attainment reduces job destruction for both types of jobs (temporary or stable jobs).

Had the education level been kept exogeneous, both unemployment rate and unemployment duration would have been higher, and there would have been more job destructions for both types of jobs. Overall, endogeneous education thus tends to reduce the negative effects of labour market regulations, a quite intuitive result. Note, however, that this can be true only if the workforce remains employable after the rise in labour market rigidities. As the unemployable would not get any return from their educational investment, they would not make any effort,

\footnotetext{
${ }^{18}$ The pictures of the two curves can easily be drawn for the parameter values considered here. An implicit plot is reported in appendix for the benchmark case.
} 
and educational investments would drop in such a case, as can be inferred from equation (30). It is also worth remarking that job creation is monotonic and decreasing in firing costs when education is exogeneous as depicted on panel a in Figure 7. This result does not necessarily hold when education is endogeneous. We further discuss this point below.

As a robustness check, we let also the parameter $a_{1}$ in the production function $y(e)=a_{0} e^{a_{1}}$ vary ${ }^{19}$. When higher (lower) values for such a parameter are considered, this tends to magnify (reduce) the beneficial effect of firing costs on education. Indeed, this is a quite intuitive property given that for an arbitrarily low value of $a_{1}$ which tends to zero, we are back to a model with exogeneous education where all the potentially beneficial effect of firing costs on productivity disappear. In the converse case where $a_{1}$ is chosen arbitrarily large, the beneficial effect of firing costs on productivity is magnified and may even be so high that labour market tightness $\theta$ increases with $f$, at least over some range.

[Figure 8 about here]

This can be seen from Figure 8 where we have chosen a value of $a_{1}$ such that the relationship between firing costs and labour market tightness $\theta$ is monotonic and increasing. At the same time, we see from this figure that the effect of the approval rate of temporary contracts $p$ on $\theta$ may depend on the value of firing costs: a rise in $p$ appears to be detrimental to education for any value of firing costs as depicted on panel $b$.

We can therefore conclude that though the effect of firing costs is globally ambiguous, it could even reduce the unemployment rate and even unemployment duration in some cases, though this probably looks more like a theoretical exercise rather than an empirical fact, given that (i) most studies find an ambiguous effect on unemployment and a positive effect on unemployment duration (ii) arbitrarily high values for $a_{1}$ can be ruled out empirically by the studies on the return to education where a reasonable estimate for such a return does not generally exceed $10 \%$ (see e.g. Card, 2001).

\section{Welfare analysis}

In this section, we investigate the welfare effects of firing costs and dual employment contracts. We show that firing costs may be welfare improving to the extent that it encourages educational investment by stabilizing employment relationships, whereas dual employment contracts in the form of short-term vs. long term contracts may discourage educational investments and therefore lead to a welfare loss.

In this purpose, we restrict ourselves to the case where $\rho=0$. In this case, aggregate welfare corresponds to aggregate output $Y$ net of search and schooling costs. Formally, we get:

$$
Y-\gamma v-\delta c(e)
$$

\footnotetext{
${ }^{19}$ Alternatively, we could have considered a change in the parameters of function $c(e)=c_{0} e^{c_{1}}$.
} 
where $Y$ denotes aggregate output evaluated in a steady-state. Aggregate output is the sum of outputs for each type of job, i.e. $Y=Y^{t}+Y^{n s}+Y^{s}$ which, at any moment in time evolve according to:

$$
\begin{aligned}
& d Y^{t} / d t=p \mu(\theta) U\left[y(e)+x_{0}\right]-(\delta+\lambda) Y_{t} \\
& d Y^{n s} / d t=(1-p) \mu(\theta) U\left[y(e)+x_{0}\right] \\
&+\lambda \bar{G}\left(x_{n s}\right) T \int_{x_{n s}}^{x_{u}}\left[y(e)+x^{\prime}\right] \frac{\mathrm{d} G\left(x^{\prime}\right)}{\bar{G}\left(x_{n s}\right)}-(\delta+\lambda) Y^{n s}
\end{aligned}
$$

At any moment in time, the unemployed can be hired on either on a temporary contract at rate $p \mu(\theta)$ or on a new stable job with probability $(1-p) \mu(\theta)$. Temporary and new stable jobs start with the same productivity level $y(e)+x_{0}$, are hit by a productivity shock at the same rate, they can also be destroyed exogeneously by the workers' death at the same rate $\delta$. In addition, a proportion $\lambda \bar{G}\left(x_{n s}\right)$ of the temporary jobs is converted into a new stable job, and starts off with a productivity which on average equals $\int_{x_{n s}}^{x_{u}}\left[y(e)+x^{\prime}\right] \frac{\mathrm{d} G\left(x^{\prime}\right)}{\bar{G}\left(x_{n s}\right)}$.

$$
d Y^{s} / d t=\lambda \bar{G}\left(x_{s}\right)(N+S) \int_{x_{s}}^{x_{u}}\left[y(e)+x^{\prime}\right] \frac{\mathrm{d} G\left(x^{\prime}\right)}{\bar{G}\left(x_{s}\right)}-(\delta+\lambda) Y^{s}
$$

Stable jobs are hit at rate $\lambda$ by productivity shocks and can be destroyed exogeneously by the worker's death at rate $\delta$. In the event of a productivity shock, a proportion $\lambda \bar{G}\left(x_{s}\right)$ of the existing stable and new stable jobs are continued with a productivity level which on average is worth $\int_{x_{s}}^{x_{u}}\left[y(e)+x^{\prime}\right] \frac{\mathrm{d} G\left(x^{\prime}\right)}{\bar{G}\left(x_{s}\right)}$ while the remaining $\lambda G\left(x_{s}\right)$ are destroyed endogeneously.

In a steady state, $d Y^{t} / d t=d Y^{n s} / d t=d Y^{s} / d t=0$, so that aggregate output $Y$ writes down:

$$
\begin{aligned}
Y= & \frac{\mu(\theta)}{\delta+\lambda} U\left[y(e)+x_{0}\right]+\frac{\lambda}{\delta+\lambda} T \int_{x_{n s}}^{x_{u}}\left(y(e)+x^{\prime}\right) \mathrm{d} G\left(x^{\prime}\right) \\
& +\frac{\lambda}{\delta+\lambda}(N+S) \int_{x_{s}}^{x_{u}}\left(y(e)+x^{\prime}\right) \mathrm{d} G\left(x^{\prime}\right)
\end{aligned}
$$

$U, T, N, S$ are given by the flow equilibrium equations (19) to (23). Our welfare criterion to be maximized is then

$$
Y-\gamma \theta U-\delta c(e)
$$

The welfare properties of the economy are studied in two steps. As a first step, we study the welfare properties of a laissez-faire economy, i.e. an economy without firing costs nor temporary contracts. We show that such an economy is inefficient and that there is too much job destruction. The welfare effects of EPL are then considered in the second step.

\subsection{The inefficiency of the laissez-faire economy}

We first study the welfare properties of the laissez-faire equilibrium where $(p, f)=(0,0)$. In this case, the objective of the planner simplifies to:

$$
\max _{x, \theta, e}<\frac{\mu(\theta) U}{\delta+\lambda}\left[y(e)+x_{0}\right]+\frac{\lambda(1-U)}{\delta+\lambda} \int_{x}^{x_{u}}\left(y(e)+x^{\prime}\right) \mathrm{d} G\left(x^{\prime}\right)-\gamma \theta U-\delta c(e)>
$$


This maximization problem is subject to the same constraint on labour market flows as the decentralized economy, i.e. $U=\frac{\delta+\lambda G(x)}{\delta+\lambda G(x)+\mu(\theta)}$. Let $x^{p}, \theta^{p}$ and $e^{p}$ denote the values of the endogeneous variables chosen by the social planner. Those values solve the following set of equations:

\section{Efficiency}

(i) Efficient job creation

$$
\frac{\gamma}{\eta\left(\theta^{p}\right)}=\left(1-\alpha^{p}\right) \frac{x_{0}-x^{p}}{\delta+\lambda}
$$

(ii) Efficient job destruction

$$
0=(\delta+\lambda) y\left(e^{p}\right)+x^{p}\left(\delta+\alpha^{p} \mu\left(\theta^{p}\right)\right)+\lambda x_{u}-\alpha^{p} \mu\left(\theta^{p}\right) x_{0}-\lambda \int_{x^{p}}^{x^{u}} G(x) \mathrm{d} x
$$

(iii) Efficient educational investments

$$
\frac{\mu\left(\theta^{p}\right)}{\delta+\lambda G\left(x^{p}\right)+\mu\left(\theta^{p}\right)} \frac{y^{\prime}\left(e^{p}\right)}{\delta}=c^{\prime}\left(e^{p}\right)
$$

where $\alpha^{p}=-\theta^{p} \frac{\eta^{\prime}\left(\theta^{p}\right)}{\eta\left(\theta^{p}\right)}$. Those values can be directly compared to those obtained in the laissezfaire equilibrium. Let $x^{*}, \theta^{*}$ and $e^{*}$ denote the equilibrium values of the key endogeneous variables. Those values solve the following set of equations:

\section{Laissez-faire}

(i) Job creation in the laissez-faire economy

$$
\frac{\gamma}{\eta\left(\theta^{*}\right)}=(1-\beta) \frac{x_{0}-x_{s}^{*}}{\delta+\lambda}
$$

(ii) Job destruction in the laissez-faire economy

$$
0=(\delta+\lambda) y\left(e^{*}\right)+\lambda x_{u}-\beta \mu\left(\theta^{*}\right) x_{0}+x_{s}^{*}\left(\delta+\beta \mu\left(\theta^{*}\right)\right)-\lambda \int_{x_{s}^{*}}^{x^{u}} G(x) \mathrm{d} x
$$

(iii) Education Effort in the laissez-faire economy

$$
\frac{\beta \mu\left(\theta^{*}\right)}{\delta+\lambda+\beta \mu\left(\theta^{*}\right)} \frac{y^{\prime}\left(e^{*}\right)}{\delta}=c^{\prime}\left(e^{*}\right)
$$

The comparison of job creation and job destruction equations in the equilibrium and centralized outcomes is standard. For a given education level, the equilibrium is constrained efficient provided the Hosios-Diamond-Pissarides (HDP) condition $\beta=\alpha$ holds.

However, the comparison of equation (58) and (61) is more instructive: at given tightness, the decentralized outcome does not yield sufficient educational incentives compared to the socially efficient level. We can conclude that the laissez-faire equilibrium is inefficient, and that the HDP 
condition is not sufficient to guarantee efficiency. In this model, too little education $\left(e^{*}<e^{p}\right)$ implies excess job destruction $\left(x^{p}<x^{*}\right)$ and insufficient job creation $\left(\theta^{p}>\theta^{*}\right)$. Otherwise stated, the economy considered here is no more efficient when educational investments are taken into account even if the HDP condition is satisfied.

Note that this is in contrast with the properties of a frictionless economy, where workers are paid their marginal product and where both private and social returns to education coincide, as in Becker (1964). Search frictions lead to a non competitive wage setting, and Nash bargaining creates a wedge between private and social returns to education. In other words, workers are held up in the decentralized economy (see e.g. Williamson, 1975, Grout, 1984, Malcolmson, 1997), as they invest in education ex ante and ex post wage bargaining implies some degree of rent sharing. As workers bear alone the full cost of their education, and get only a share of the reward, the decentralized education efforts are insufficient compared to the optimum. Such a phenomenon is pervasive in the literature on frictional unemployment (e.g. Acemoglu, $1996^{20}$ ), the novelty being here that the result is extended to a framework with endogeneous job destruction $^{21}$. In our framework, excess job destruction suggests that their may be a rationale for some degree of employment protection, even if the first best policy corresponds to an education policy aimed at subsidizing education efforts ${ }^{22}$.

Two remarks are in order. First, note that the hold-up problem cannot be solved by giving all the bargaining power to either one of the two parties. Namely, when $\beta$ tends to 0 ,workers do not get any return to their investments, and as a result, do not undertake any investment in education at all. From the free entry condition, this implies that tightness tends to zero in such a case. Likewise, when workers have all the bargaining power, firms have no incentive to advertise vacancies and again, tightness tends to zero in that case. In turn, this implies that the return to education tends to zero and that workers do not invest in education.

It may also be noted that in the particular case where search frictions die down (e.g. when the scale parameter of the matching function $k$ tends to infinity), our frictional economy tends to the particular case of a perfectly competitive framework where workers are paid their marginal product, and where private investments in education are socially optimal, as in Becker (1964). Indeed, when frictions become negligible, it takes no time for firms and workers to match with a partner ${ }^{23}$. For workers, this implies that they are paid their full marginal product in such a case, as their outside options in the wage bargain become infinite. As a result, the hold up problem vanishes as workers get the full reward to their educational investments. Meanwhile,

\footnotetext{
${ }^{20}$ See also Masters (1998), Acemoglu and Shimer (1999) and Acemoglu (2001) for models where firms may also be held up, a case we do not consider here.

${ }^{21}$ As highlighted by Acemoglu and Shimer (1999) the hold up problem may be solved by a market mechanism in some cases, when search can be directed towards different matching markets while the quantity of investment undertaken in each sub-market can be perfectly observed. Random matching is a strong assumption in this respect, but perfect observability/market completeness are probably as strong assumptions.

${ }^{22}$ Imagine that for some reasons, there are some constraints on the finance of the education policy. In this case, there may be room for some degree of employment protection, even if this is clearly not a first best policy.

${ }^{23}$ The properties of the matching process imply that both $\mu(\theta)$ and $\eta(\theta)$ tend to infinity when the scale parameter of the matching function tends to infinity.
} 
all the distortions involved by the matching process become negligible, as it now takes no time to match with a partner in this limit case. Otherwise stated, our frictional framework embeds the competitive equilibrium as a particular case when frictions become infinitely small. In such a case, we are back to Becker's result according to which private education choices are socially efficient.

This being established, we turn to the welfare effects of an European-style of employment protection with dual labour contracts.

\subsection{Welfare effects of employment protection}

Given that there can be some excess job destruction, there may be room for employment protection legislations. Again, we are interested in quantifying those effects. Relying on the same parameter set as in the previous section, we depict the effects of respectively changing the importance of firing costs and/or changing the approval rate of temporary jobs in the economy, i.e. we let $(p, f)$ vary from $(0,0)$ to $(1,1)$. The results are reported on Figure 9.

[Figure 9 about here]

It turns out that firing costs may indeed improve welfare compared to the laissez-faire economy, because stabilizing employment relationships may spur education investments, as the first row of Figure 9 illustrates. A few remarks are in order. First, this result is in contrast with the standard result obtained with exogeneous education (see e.g. Mortensen and Pissarides, 1999, Pissarides, 2000), where the HDP condition $\beta=\alpha$ is sufficient to guarantee constrained efficiency, and where introducing firing costs is always inefficient.

For the need of the comparison, we have depicted on the second row of Figure 9 the welfare effect of $f$ and $p$ when education is kept constant. In this case, constrained efficiency obtains under the laissez-faire equilibrium where $(p, f)=(0,0)$, and welfare is always decreased by a rise in $f$ and/or $p$.

On the contrary, it can be shown on first row of Figure 9 that the positive effect stemming from human capital investment may justify the existence of EPL in our framework, and that for reasonably moderate values of firing penalties, a rise in $f$ can be welfare improving compared to the laissez-faire case.

However, note that the first best policy to restore efficiency in this framework is an education policy aimed at subsidizing education attainment. EPL is only desirable to the extent that an education policy cannot be implemented, and under the assumption that workers remain employable in spite of the rise in labour market rigidities. In any case, the optimum obtains for $f>0$ and $p=0$, i.e. it is never optimal to let $p$ be positive, given its negative effect on human capital investments and job destruction.

Otherwise stated, we see from the upper part of Figure 9 that the beneficial effect of EPL on welfare is reduced when $p>0$. This looks like a rather intuitive result, given that the inefficient laissez faire economy is characterized by too little job creation and too much job destruction due to insufficient education investment. There is less chance that a rise in firing costs improves 
welfare when $p>0$, given that a rise in firing costs reduces job destruction for long-term jobs but increases job termination for temporary contracts, a distortion which does not take place when $p=0$. Dualism on the labour market does not seem desirable from this perspective.

\section{Conclusion}

In this paper, we have studied the impact of an European-like labour market regulation on the return to schooling, equilibrium unemployment and welfare. Compared to some of the previous contributions on this topic (e.g. Blanchard and Landier, 2002, Cahuc and Postel-Vinay, 2002), our model provides an analysis of the impact of dual labour market on the incentives to schooling, and shows that firing costs and temporary jobs have opposite effects on the rate of use of human capital, and thus on educational investments. We furthermore demonstrate that the equilibrium is not necessarily unique because of the positive interactions between education and job destruction. As a consequence, the economy may be stuck in a low-skill trap when EPL is too coercive. Finally, and in opposition to the previous literature, we show that a laissez faire economy with no regulation is inefficient as it is characterized by suboptimal educational investments leading to excess job destruction and insufficient job creation. Hence, by stabilizing employment relationships, firing costs may spur educational investments and therefore lead to welfare and productivity gains. However, there is little chance for a dual labour market as is common in many European countries with heavily regulated long-term contracts and more flexible short-term contracts to raise the incentives to schooling and to increase aggregate welfare. 


\section{Appendix}

Intermediate calculations After a few calculations, using asset values and surpluses definitions, we get :

$$
\begin{gathered}
(r+\lambda) \Omega^{s}(x, e)=y(e)+x+\lambda \int_{x_{l}}^{x_{u}} \max \left\{\Omega^{s}\left(x^{\prime}, e\right), 0\right\} \mathrm{d} G\left(x^{\prime}\right)-r W^{u}+r f \\
(r+\lambda) \Omega^{n s}(x, e)=y(e)+x+\lambda \int_{x_{l}}^{x_{u}} \max \left\{\Omega^{s}\left(x^{\prime}, e\right), 0\right\} \mathrm{d} G\left(x^{\prime}\right)-r W^{u}-\lambda f \\
(r+\lambda) \Omega^{t}\left(x_{0}, e\right)=y(e)+x+\lambda \int_{x_{l}}^{x_{u}} \max \left\{\Omega^{s}\left(x^{\prime}, e\right), 0\right\} \mathrm{d} G\left(x^{\prime}\right)-r W^{u}
\end{gathered}
$$

From those definitions, combined with the expressions of the surplus (62) to (63), we get:

$$
\begin{gathered}
\Omega^{s}(x, e)-\Omega^{s}\left(x_{s}, e\right)=\Omega^{s}(x, e)=\frac{x-x_{s}}{r+\lambda} \\
\Omega^{n s}(x, e)-\Omega^{n s}\left(x_{n s}, e\right)=\Omega^{n s}(x, e)=\frac{x-x_{n s}}{r+\lambda} \\
(r+\lambda) \Omega^{s}(x, e)=y(e)+x+\lambda \int_{x_{s}}^{x_{u}} \frac{x^{\prime}-x_{s}}{r+\lambda} \mathrm{d} G\left(x^{\prime}\right)-r W^{u}+r f \\
(r+\lambda) \Omega^{n s}(x, e)=y(e)+x+\lambda \int_{x_{s}}^{x_{u}} \frac{x^{\prime}-x_{s}}{r+\lambda} \mathrm{d} G\left(x^{\prime}\right)-r W^{u}-\lambda f \\
(r+\lambda) \Omega^{t}\left(x_{0}, e\right)=y(e)+x_{0}+\lambda \int_{x_{n s}}^{x_{u}} \frac{x^{\prime}-x_{n s}}{r+\lambda} \mathrm{d} G\left(x^{\prime}\right)-r W^{u}
\end{gathered}
$$

Using expression (62) for the surplus, the above definitions and (65) we get the following expressions for the productivity thresholds $x_{s}$ and $x_{n s}$ :

$$
\begin{gathered}
0=y(e)+x_{s}+\lambda \int_{x_{s}}^{x_{u}} \frac{x-x_{s}}{r+\lambda} \mathrm{d} G\left(x^{\prime}\right)-r W^{u}+r f \\
x_{n s}=x_{s}+(r+\lambda) f
\end{gathered}
$$

We can now calculate the expressions for $r W^{u}$. We have :

$$
r W^{u}=\beta \mu(\theta)\left[p \Omega^{t}\left(x_{0}, e\right)+(1-p) \Omega^{n s}\left(x_{0}, e\right)\right]
$$

Making use of (68) and (69), we get

$$
r(r+\lambda) W^{u}=\beta \mu(\theta)\left[\begin{array}{c}
y(e)+x_{0}+\lambda p \int_{x_{n} s}^{x_{u}} \frac{x^{\prime}-x_{n s}}{r+\lambda} \mathrm{d} G\left(x^{\prime}\right) \\
+\lambda(1-p) \int_{x_{s}}^{x_{u}} \frac{x^{\prime}-x_{s}}{r+\lambda} \mathrm{d} G\left(x^{\prime}\right)-r W^{u}-\lambda(1-p) f
\end{array}\right]
$$

which implies

$$
r(r+\lambda+\beta \mu(\theta)) W^{u}=\beta \mu(\theta)\left[\begin{array}{c}
y(e)+x_{0}+\lambda p \int_{x_{n s}}^{x_{u}} \frac{x^{\prime}-x_{n s}}{r+\lambda} \mathrm{d} G\left(x^{\prime}\right) \\
+\lambda(1-p) \int_{x_{s}}^{x_{u}} \frac{x^{\prime}-x_{s}}{r+\lambda} \mathrm{d} G\left(x^{\prime}\right)-\lambda(1-p) f
\end{array}\right]
$$

Reinserting in (70) and after integration by part, we get

$$
\begin{aligned}
0= & x_{s}(r+\beta \mu(\theta))+y(r+\lambda)-\beta \mu(\theta) x_{0}+\lambda x_{u} \\
& +(r+\lambda)(r+\beta \mu(\theta)) f+\lambda \beta \mu(\theta) p \int_{x_{n s}}^{x^{u}} \frac{G(x)}{r+\lambda} \mathrm{d} x-\lambda(r+\lambda+\beta \mu(\theta) p) \int_{x_{s}}^{x^{u}} \frac{G(x)}{r+\lambda} \mathrm{d} x
\end{aligned}
$$

which corresponds to the expressions in the corpus of the paper. 
Partial equilibrium properties of $x_{s}$ and $x_{n s}$. The comparative statics properties for $x_{s}$ result from the implicit function theorem applied to expression (73). The comparative statics for $x_{n s}=x_{s}+(r+\lambda) f$ can then be deduced. In particular, we have

$$
\begin{gathered}
x_{n s}^{\prime}(e)=x_{s}^{\prime}(e)=\frac{-(r+\lambda) y^{\prime}(e)}{r+\lambda G\left(x_{s}\right)\left(1+\frac{p \beta \mu(\theta)}{r+\lambda}\right)+\beta \mu(\theta)\left(1-p \frac{\lambda G\left(x_{n s}\right)}{r+\lambda}\right)} \leq 0 \\
\frac{d x_{s}}{d f}=\frac{-\lambda \beta \mu(\theta) p G\left(x_{n s}\right)}{r+\lambda G\left(x_{s}\right)\left(1+\frac{p \beta \mu(\theta)}{r+\lambda}\right)+\beta \mu(\theta)\left(1-p \frac{\lambda G\left(x_{n s}\right)}{r+\lambda}\right)} \leq 0 \\
\frac{d x_{n s}}{d f}=\frac{d x_{s}}{d f}+(r+\lambda) \geq 0 \\
\frac{d x_{s}}{d p}=\frac{d x_{n s}}{d p}=\frac{\lambda \beta \mu(\theta)\left[\int_{x_{s}}^{x_{u}} \frac{G(x)}{r+\lambda} \mathrm{d} x-\int_{x_{s}+(r+\lambda) f}^{x_{u}} \frac{G(x)}{r+\lambda} \mathrm{d} x\right]}{r+\lambda G\left(x_{s}\right)\left(1+\frac{p \beta \mu(\theta)}{r+\lambda}\right)+\beta \mu(\theta)\left(1-p \frac{\lambda G\left(x_{n s}\right)}{r+\lambda}\right)} \geq 0 \\
\frac{d x_{s}}{d \beta}=\frac{d x_{n s}}{d \beta}=\frac{-\mu(\theta)\left[x_{s}-x_{0}+(r+\lambda) f+\lambda\left[\int_{x_{s}}^{x_{u}} \frac{G(x)}{r+\lambda} \mathrm{d} x-\int_{x_{s+(r+\lambda) f}}^{x_{u}} \frac{G(x)}{r+\lambda} \mathrm{d} x\right]\right]}{r+\lambda G\left(x_{s}\right)\left(1+\frac{p \beta \mu(\theta)}{r+\lambda}\right)+\beta \mu(\theta)\left(1-p \frac{\lambda G\left(x_{n s}\right)}{r+\lambda}\right)} \geq 0 \\
\frac{d x_{s}}{d \theta}=\frac{d x_{n s}}{d \theta}=\frac{-\beta \eta(\theta)(1-\alpha)\left[x_{s}-x_{0}+(r+\lambda) f+\lambda\left[\int_{x_{s}}^{x_{u}} \frac{G(x)}{r+\lambda} \mathrm{d} x-\int_{x_{s+(r+\lambda) f}}^{x_{u}} \frac{G(x)}{r+\lambda} \mathrm{d} x\right]\right]}{r+\lambda G\left(x_{s}\right)\left(1+\frac{p \beta \eta(\theta)}{r+\lambda}\right)+\beta \mu(\theta)\left(1-p \frac{\lambda G\left(x_{n s}\right)}{r+\lambda}\right)} \geq 0
\end{gathered}
$$

Partial equilibrium properties of the return to schooling $R$ see section 3 .

Equilibrium properties : existence and uniqueness. Equation (43) implicitly defines $x_{s} \equiv$ $x_{s}(\theta)$, with $x_{s}^{\prime}(\theta)=\frac{-\gamma \eta^{\prime}(\theta)(r+\lambda)}{\eta(\theta)^{2}(1-\beta)\left[-1+\frac{\lambda p\left[G\left(x_{s}\right)-G\left(x_{n s}\right)\right]}{r+\lambda}\right]} \leq 0$. Keeping in mind that $x_{s} \equiv x_{s}(\theta) \in$ $\left[x_{l}, x_{u}\right]$ and reporting in equations (39) and (41), we get a system of two equations and two main unknowns :

$$
\begin{aligned}
0= & y\left(e^{*}\right)-\frac{\beta \mu\left(\theta^{*}\right)}{r+\lambda} x_{0}+x_{s}^{*}\left(\theta^{*}\right) \frac{r+\beta \mu\left(\theta^{*}\right)}{r+\lambda}+\frac{\lambda}{r+\lambda} x_{u}+\left(r+\beta \mu\left(\theta^{*}\right)\right) f \\
& -\frac{r+\lambda+\beta p \mu\left(\theta^{*}\right)}{r+\lambda} \int_{x_{s}^{*}\left(\theta^{*}\right)}^{x_{u}} \frac{\lambda}{r+\lambda} G(x) \mathrm{d} x+\frac{p \beta \mu\left(\theta^{*}\right)}{r+\lambda} \int_{x_{s}^{*}\left(\theta^{*}\right)+(r+\lambda) f}^{x_{u}} \frac{\lambda}{r+\lambda} G(x) \mathrm{d} x
\end{aligned}
$$

and

$$
\frac{\beta \mu\left(\theta^{*}\right)}{r+\lambda+\beta \mu\left(\theta^{*}\right)} \frac{y^{\prime}\left(e^{*}\right)}{r}\left[1+\frac{\lambda\left[p\left(1-G\left(x_{s}\left(\theta^{*}\right)+(r+\lambda) f\right)\right)+(1-p)\left(1-G\left(x_{s}^{*}\left(\theta^{*}\right)\right)\right)\right]}{r+\lambda G\left(x_{s}^{*}\left(\theta^{*}\right)\right)\left(1+\frac{p \beta \mu\left(\theta^{*}\right)}{r+\lambda}\right)+\beta \mu\left(\theta^{*}\right)\left(1-p \frac{\lambda G\left(x_{s}\left(\theta^{*}\right)+(r+\lambda) f\right)}{r+\lambda}\right)}\right]=c^{\prime}\left(e^{*}\right)
$$

Let $e_{1}(\theta)$ be the solution to (74) (the LD curve) and $e_{2}(\theta)$ solve (75) (the OS curve).

Step 1: properties of $e_{1}(\theta)$.

(i) $e_{1}(\theta)$ is strictly increasing in $\theta$, i.e. $e_{1}^{\prime}(\theta) \geq 0$. Namely, $e_{1}(\theta)$ is a solution to $\Psi_{1}(e, \theta)=0$, where $\frac{d \Psi_{1}}{d e} \geq 0$ and $\frac{d \Psi_{1}}{d \theta} \leq 0$ from (74) to which the implicit function theorem applies. 
(ii) it admits the following boundary properties: $\lim _{\theta \rightarrow 0} y\left(e_{1}\right)=\lim _{\theta \rightarrow 0} \frac{\lambda}{r+\lambda} \int_{x_{s}(\theta)}^{x_{u}} G(x) \mathrm{d} x-\frac{\lambda}{r+\lambda} x_{u}-$ $r f-\frac{r}{r+\lambda} x_{s}(\theta)=\underline{y}(\theta)$ and $\lim _{\theta \rightarrow+\infty} y\left(e_{1}\right)=\lim \frac{\beta \gamma \theta}{1-\beta}+\frac{\lambda}{r+\lambda} \int_{x_{s}(\theta)}^{x_{u}} G(x) \mathrm{d} x-\frac{\lambda}{r+\lambda} x_{u}-r f-$ $\frac{r}{r+\lambda} x_{s}(\theta)$. As $x_{s}(\theta) \in\left[x_{l}, x_{u}\right]$ it necessarily remains finite and so does $\lim _{\theta \rightarrow+\infty} x_{s}(\theta)$. As a result $\lim _{\theta \rightarrow+\infty} y\left(e_{1}\right)=+\infty$.

(iii) If $\underline{y}(0) \geq 0$ then $e_{1}$ is defined over $\left[0,+\infty\right.$ [. If $\underline{y}(0)<0$, then $e_{1}$ is defined over $[\underline{\theta},+\infty[$ where $\underline{\theta}$ solves :

$$
\begin{aligned}
0= & -x_{0} \frac{\beta \mu(\underline{\theta})}{r+\lambda}+x_{s}(\underline{\theta}) \frac{r+\beta \mu(\underline{\theta})}{r+\lambda}+\frac{\lambda}{r+\lambda} x_{u}+(r+\beta \mu(\underline{\theta})) f \\
& -\frac{r+\lambda+\beta p \mu(\underline{\theta})}{r+\lambda} \int_{x_{s}(\underline{\theta})}^{x_{u}} \frac{\lambda}{r+\lambda} G(x) \mathrm{d} x+\frac{\beta p \mu(\underline{\theta})}{r+\lambda} \int_{x_{s}(\underline{\theta})+(r+\lambda) f}^{x_{u}} G(x) \mathrm{d} x
\end{aligned}
$$

Step 2: properties of $e_{2}(\theta)$.

(i) $e_{2}(\theta)$ is strictly increasing in $\theta$, i.e. $e_{2}^{\prime}(\theta) \geq 0$. Namely, $e_{2}(\theta)$ is a solution to $\Psi_{2}(e, \theta)=0$, where $\frac{d \Psi_{2}}{d e} \leq 0$ and $\frac{d \Psi_{2}}{d \theta} \geq 0$ from (75). The result follows from the implicit function theorem.

(ii) it admits the following boundary properties : $\lim _{\theta \rightarrow 0} y^{\prime}\left(e_{2}\right)=+\infty$ which implies $\lim _{\theta \rightarrow 0} e_{2}=0$ and $\lim _{\theta \rightarrow+\infty} y^{\prime}\left(e_{2}\right)=r c^{\prime}\left(e_{2}\right)$. Define $g\left(e_{2}\right)=y^{\prime}\left(e_{2}\right) / c^{\prime}\left(e_{2}\right)$ then $\lim _{\theta \rightarrow+\infty} e_{2}=g^{-1}(r)$.

Step 3: conclusion. $e_{1}(\theta)$ and $e_{2}(\theta)$ being continuous, an equilibrium always exists when $\underline{y}(0) \leq 0$. When $\underline{y}(0)>0$, either there is no equilibrium or there may be more than one equilibrium.

\section{Equilibrium properties : comparative statics}

Step 1: comparative statics properties of the LD curve. Shifts in the LD curve can be determined by examining the behaviour of its intercept. Inspecting $y(0)$, it can be shown that $\frac{d y(0)}{d f} \geq 0$ while $\frac{d y(0)}{d p} \leq 0$. Therefore the intercept increases with $f$ and decreases with $p$, and LD can move up with firing costs $f$ and down with the approval rate $p$ in the $(\theta, e)$ plane.

Step 2: comparative statics properties of the OS curve. Shifts in the OS curve can be determined by studying the general equilibrium properties of the return to education $R$. Recall that equation (43) implicitly defines $x_{s} \equiv x_{s}(\theta)$, and that the function is parameterized by $f$ and $p$. Likewise, it is possible to define $x_{n s} \equiv x_{n s}(\theta)$ from (43), the latter function being parameterized by $f$ and $p$. From (43) thus get that $x_{n s}$ and $x_{s}$ are decreasing with $f$ and increasing with $p$. This implies that in equilibrium :

$$
\frac{d R}{d f}=\frac{\partial R}{\partial \underset{n s}{x_{n s}}} \frac{\partial x_{n s}}{\partial f}+\frac{\partial R}{\partial x_{s}} \frac{\partial x_{s}}{\partial f} \geq 0
$$


In the same way,

$$
\frac{d R}{d p}=\frac{\partial R}{\partial x_{n s}} \frac{\partial x_{n s}}{\partial p}+\frac{\partial R}{\partial x_{s}} \frac{\partial x_{s}}{\partial p} \leq 0
$$

Therefore OS moves up with $f$ and down with $p$ in the $(\theta, e)$ plane, as argued in text.

Step 3: conclusion. Given the moves of OS and LD with respect to $f$ and $p$, we can conclude that a rise in firing costs may increase the education level $e^{*}$ and may have an ambiguous impact on tightness, depending on the magnitude of the respective moves of each curve. A rise in the approval rate $p$ may reduce the education level $e^{*}$ and has an ambiguous impact on tightness, depending on the magnitude of the move of each curve, as argued in text.

General equilibrium: Numerical Implicit Plot see section 5.1.

[Figure 10 about here]

Welfare analysis For the laissez faire equilibrium with $p=0$ and $f=0$, the welfare analysis results from the comparison of (56) to (58) with (59) to (61) as indicated in text. In the general case where $p>0$ and $f>0$, we proceed to some numerical exercise, see section 6.2 . 


\section{References}

[1] Acemoglu, D., 1996. "A microfoundation for social increasing returns in human capital accumulation", Quarterly Journal of Economics 111, 779-804.

[2] Acemoglu, D., 2001. "Good jobs vs bad jobs", Journal of Labor Economics 19, 1-21.

[3] Acemoglu, D., Shimer, R., 1999. "Holdups and efficiency with search frictions", International Economic Review 40, 827-849.

[4] Belot, M., Boone, J., Van Ours, J., 2007. "Welfare-improving employment protection", Economica 74, 381-96.

[5] Bentolila, S., Dolado, J., 1994. "Labour Flexibility and Wages: Lessons from Spain", Economic Policy 18, 55-99.

[6] Bentolila, S., Saint-Paul, G., 1992. "The macroeconomic impact of flexible labor contracts, with an application to Spain", European Economic Review 36, 1013-1047.

[7] Bertola, G., 2004. "A Pure Theory of Job Security and Labour Income Risk", Review of Economic Studies, 71, 43-61.

[8] Bentolila, S., Cahuc, P., Dolado, J., Le Barbanchon, T., 2009. Two-tier labor markets in a deep recession: France vs Spain. Mimeo

[9] Berton, F., Garibaldi, P., 2007. "Workers and firm sorting into temporary jobs", Working Paper, University of Turin.

[10] Blanchard, O.J., Landier, A., 2002. "The perverse effects of partial labour market reform: fixed-term contracts in France", Economic Journal 112, 214-44.

[11] Boeri, T., Garibaldi, P., 2007. "Two Tier Reforms of Employment Protection Legislation. A Honeymoon Effect?", Economic Journal 117, 357-385.

[12] Booth, A., Francesconi, M., Frank, J., 2002. "Temporary jobs: stepping stones or dead ends?", Economic Journal 112, 189-213

[13] Booth, A., Zoega, G., 2003. "On the welfare implications of firing costs", European Journal of Political Economy 19, 759-75.

[14] Burda, M., 1992. "A note on firing costs and severance benefits in equilibrium unemployment", Scandinavian Journal of Economics 39, 479-489.

[15] Burdett, K., Smith, E., 2002. "The low skill trap", European Economic Review 46, 1439-51.

[16] Cahuc, P., Malherbet, F., 2004, "Unemployment Compensation Finance and Labour Market Rigidity", Journal of Public Economics 88, 481-501. 
[17] Cahuc, P., Postel-Vinay, F., 2002. "Temporary jobs, employment protection and labor market performance", Labour Economics 9, 63-91.

[18] Cahuc, P., Zylberberg, A., 1999. Job Protection, Minimum Wage and Unemployment. IZA WP 95.

[19] Card, D., 2001. "Estimating the return to schooling: progress on some persistant econometric problems", Econometrica 69, 1127-1160.

[20] Charlot, O., Decreuse, B., Granier, P., 2005. "Adaptability, productivity and educational incentives in a matching model", European Economic Review 49, 1007-1032.

[21] Charlot, 0., Decreuse, B., 2005. "Self-selection in education with matching frictions". Labour Economics 12, 251-267

[22] Dolado, J.J., García-Serrano, C. Jimeno, J.F., 2002. "Drawing Lessons from the boom of temporary jobs in Spain", Economic Journal 112, 270-295.

[23] Dolado, J.J., Stucchi, F., 2008. "Do temporary contracts affect total factor productivity? Evidence from Spanish manufacturing firms", Working Paper.

[24] Farber, H., 1999. "Mobility and stability: the dynamics of job change in labor markets", in: Handbook of Labor Economics, vol 3, chapter 37, 2439-2483.

[25] Garibaldi, P., Violante, G., 2005. The Employment Effects of Severance Payments with Wage Rigidities, Economic Journal 115, 799-832,

[26] Grout, P., 1984. "Investments and wages in the absence of binding contracts: a Nash bargaining approach", Econometrica 52, 449-460.

[27] Guell, M., Petrongolo, B., 2007. "How binding are legal limits? Transitions from temporary to permanent work in Spain", Labour Economics 14, 153-183.

[28] Hosios, A., 1990. "On the efficiency of matching and related models of search and unemployment", Review of Economic Studies 57, 279-298.

[29] Lazear, E., 1990. "Job Security Provision and Employment", Quarterly Journal of Economics 105, 699-726.

[30] Malcolmson, J., 1997. "Contracts, hold up, and labor markets", Journal of Economic Literature 35, 1916-1957.

[31] Masters, A., 1998. "Efficiency of investments in human capital in a model of bilateral search and bargaining", International Economic Review 39, 477-497.

[32] Mincer, J., 1991. "Education and unemployment", NBER Working Paper 3838.

[33] Moen, E., 1999. "Education, ranking and competition for jobs", Journal of Labor Economics 17, 694-723. 
[34] Mortensen, D., Pissarides, C., 1994. "Job Creation and Job Destruction in the Theory of Unemployment", Review of Economic Studies 61, 397-415.

[35] Mortensen, D., Pissarides, C., 1999a. "Unemployment Responses to Skill-biased Technology Shocks: the Role of Labour Market Policy", Economic Journal 109, 242-65.

[36] Mortensen, D., Pissarides, C., 1999b. "New developments in models of search in the labor market", in: Handbook of Labor Economics vol 3B, chapter 39, Ashenfelter, O. and Card, D. (eds), Elsevier Science Publisher.

[37] OECD, 2002. "Taking the measure of temporary employment". Employment Outlook, chapter 3, OECD, Paris

[38] Petrongolo, B. Pissarides, C. 2001. "Looking into the black box: a survey of the matching function", Journal of Economics Literature 39, 390-440.

[39] Pissarides, C. A., 2000. Equilibrium unemployment theory, 2nd edition. MIT Press.

[40] Sala, H., Silva, J., and Toledo, M., 2008. Flexibility at the margin and labor market volatility in OECD countries. IZA working paper 3293

[41] Saint-Paul, G., 1996. Dual Labour Market : a macroeconomic perspective. MIT Press.

[42] Snower, D., 1996. "The Low-Skill, Bad-Job Trap ", in: Acquiring skills: Market failures, their symptoms and policy responses, 111-24, Cambridge University Press.

[43] Wasmer, E., 1999. "Competition for jobs in a growing economy and the emergence of dualism in employment", Economic Journal 109, 349-371.

[44] Williamson, O., 1975. Markets and hierarchies: analysis and antitrust implications. New York: Free Press. 
a. Contact rate

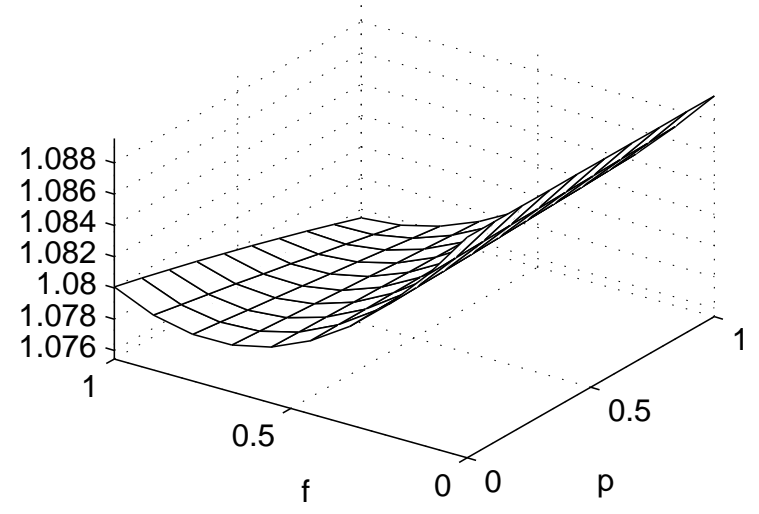

c. STJ destruction rate

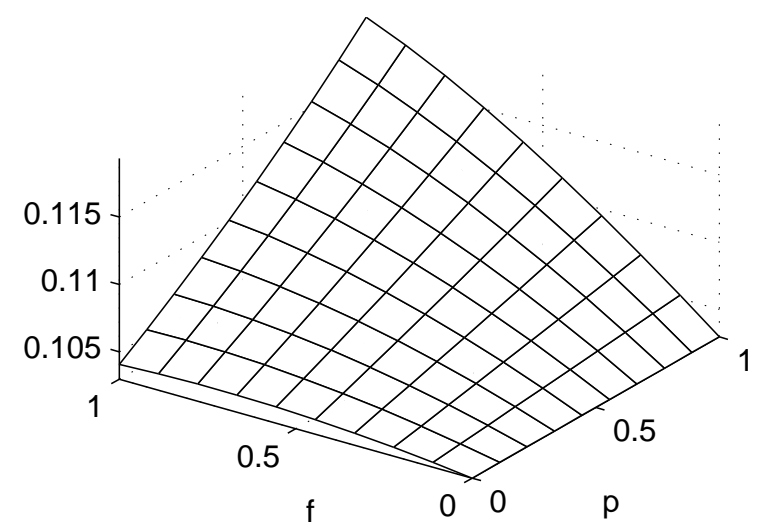

e. Unemployment rate

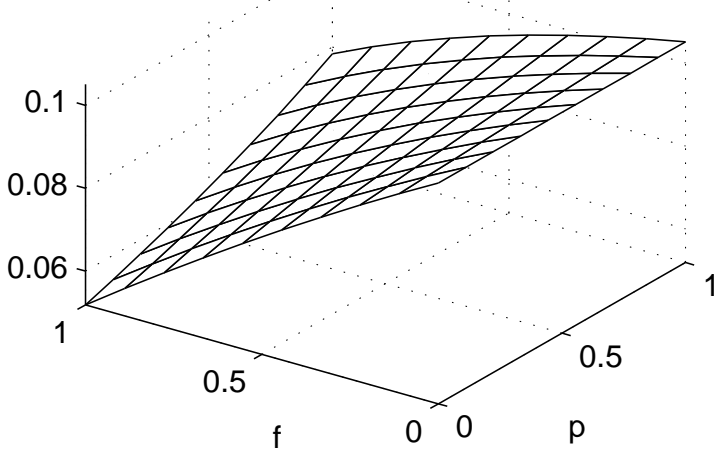

b. Education

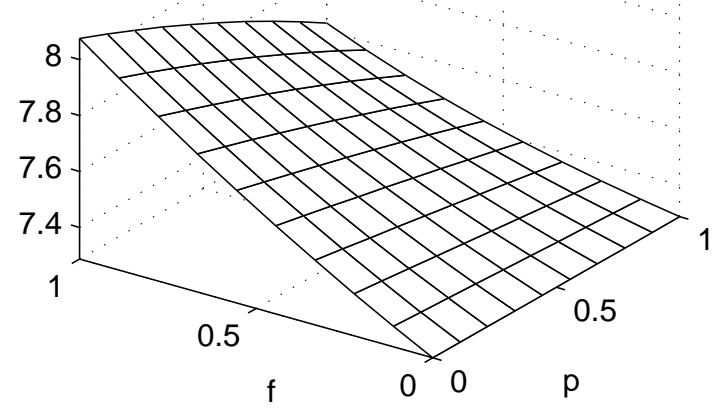

d. LTJ destruction rate

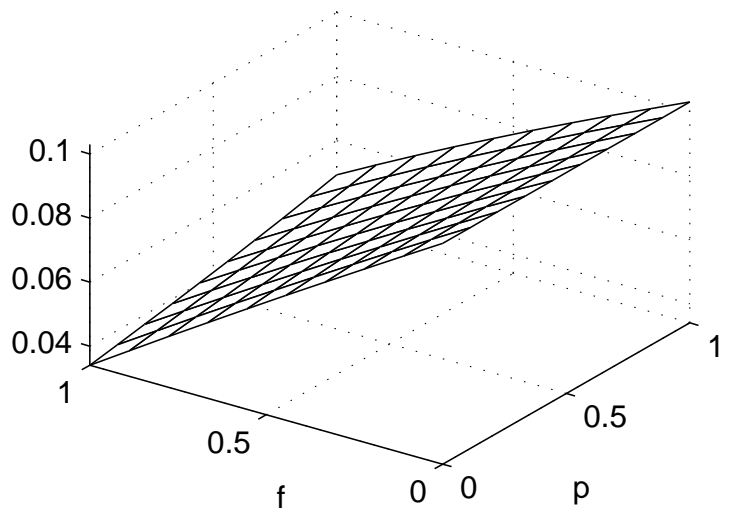

f. Share of STJ

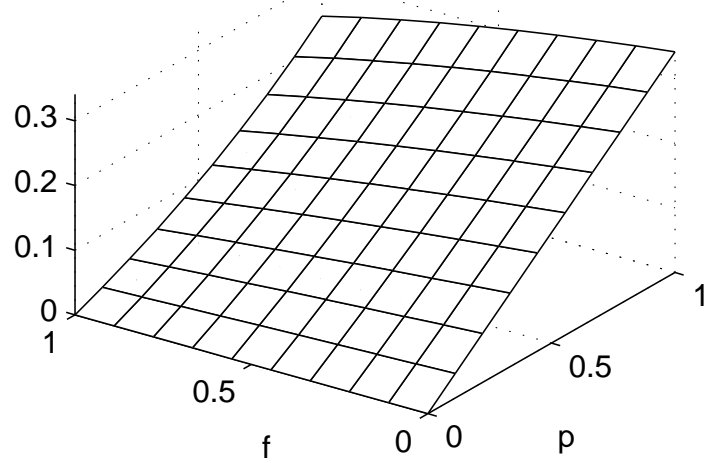

Figure 6: Effects of dual EPL when education is endogenous. STJ and LTJ stand for short term and long term jobs respectively. 
a. Contact rate

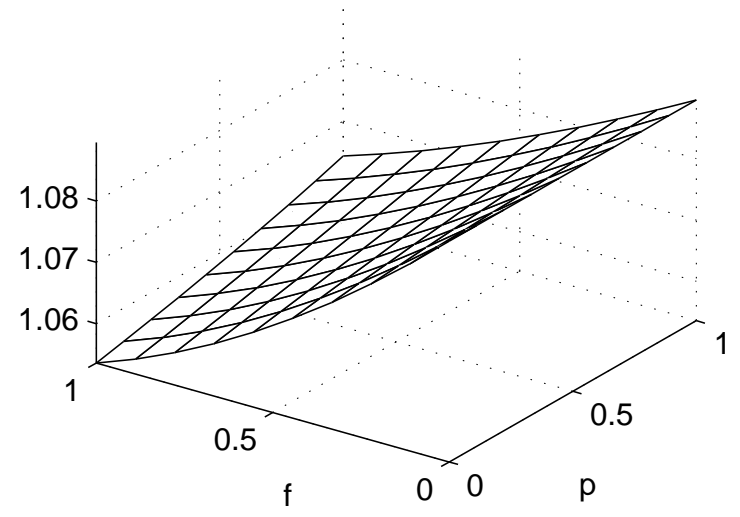

c. STJ destruction rate

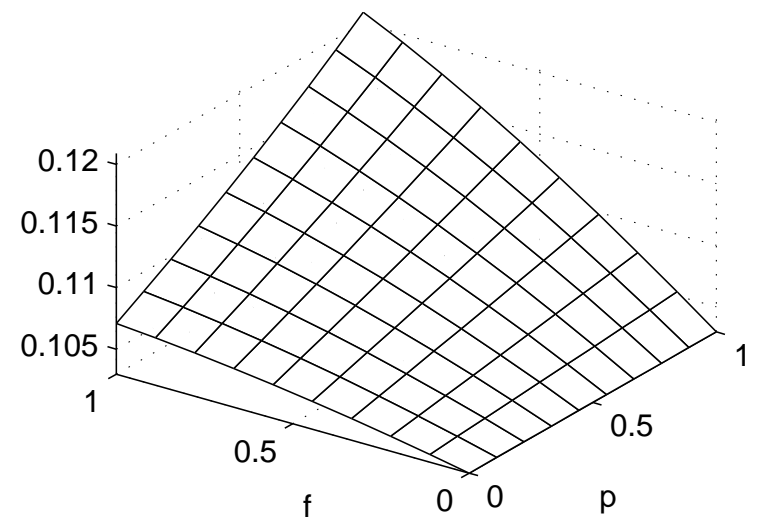

e. Unemployment rate

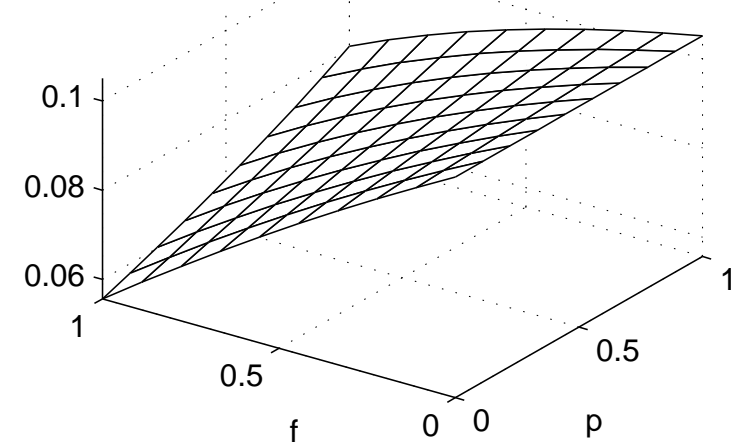

b. Education

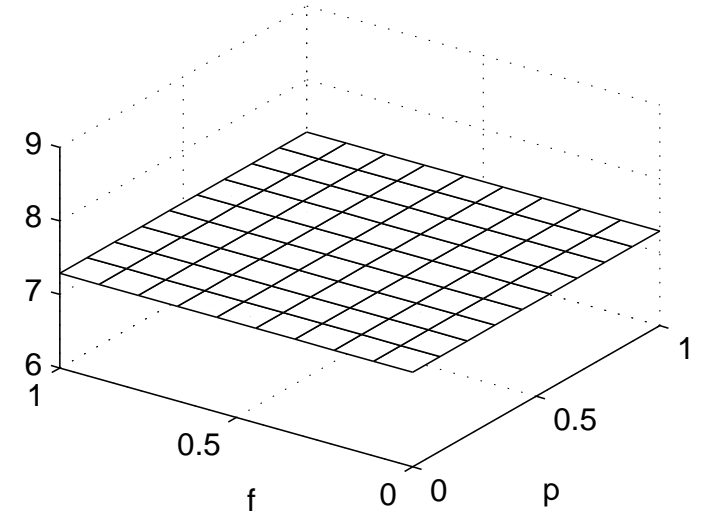

d. LTJ destruction rate

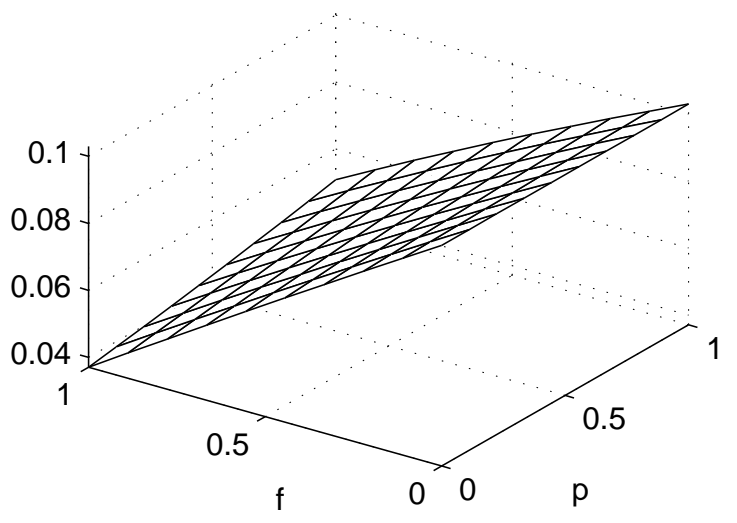

f. Share of STJ

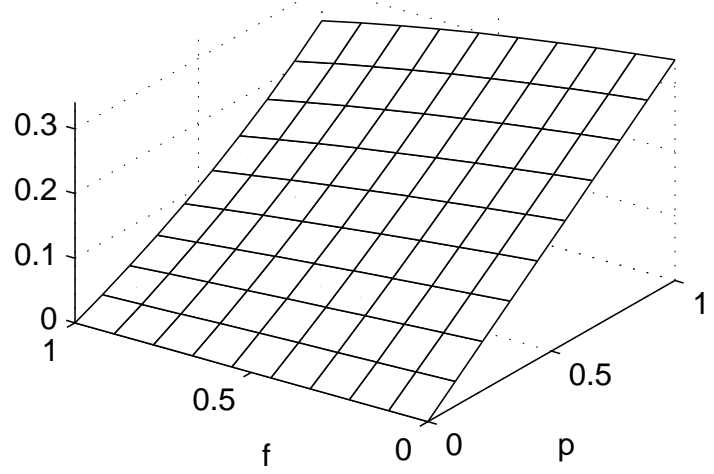

Figure 7: Effects of dual EPL when education is exogenous. STJ and LTJ stand for short term and long term jobs respectively. 
a. Contact rate

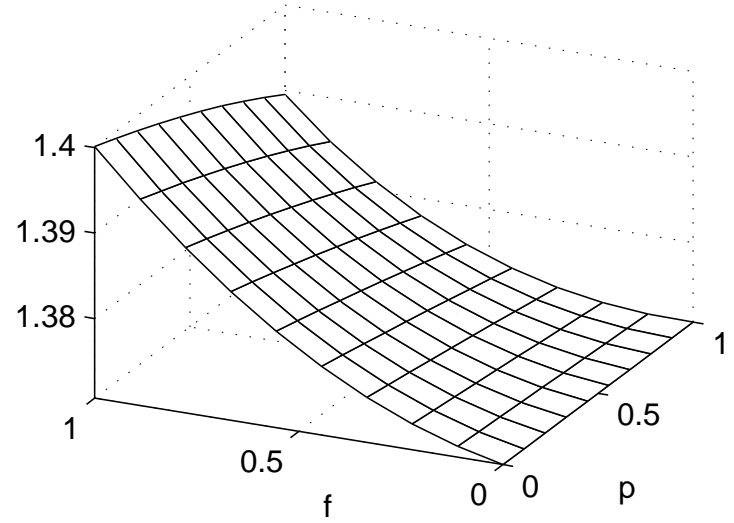

c. STJ destruction rate

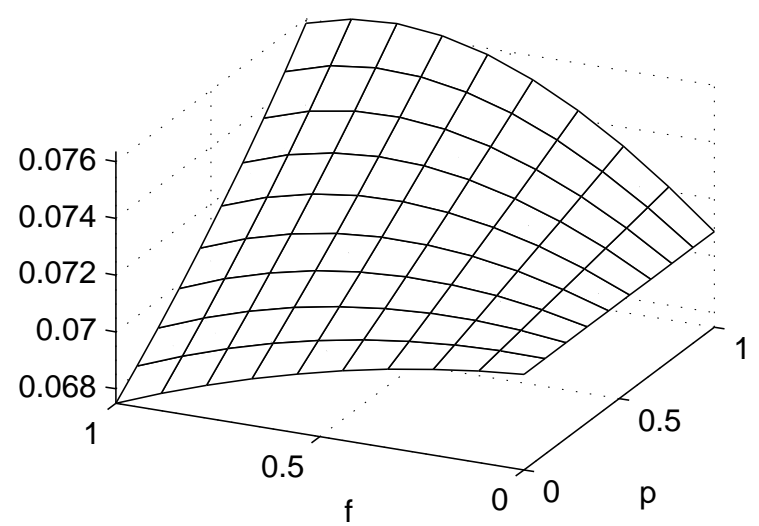

e. Unemployment rate

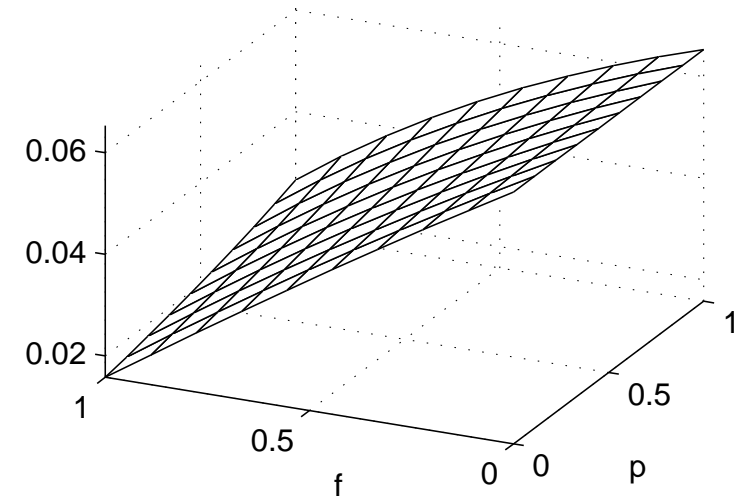

b. Education

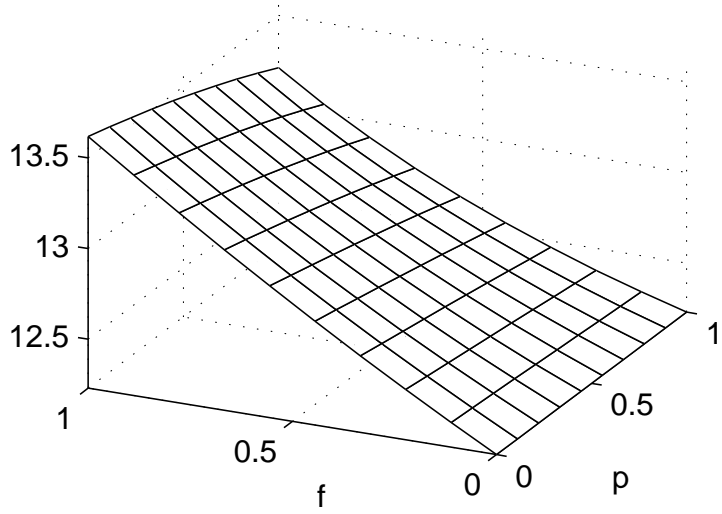

d. LTJ destruction rate

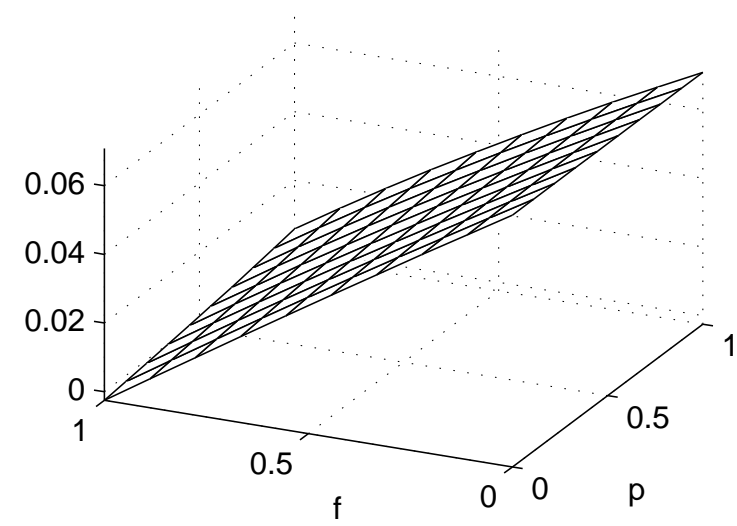

f. Share of STJ

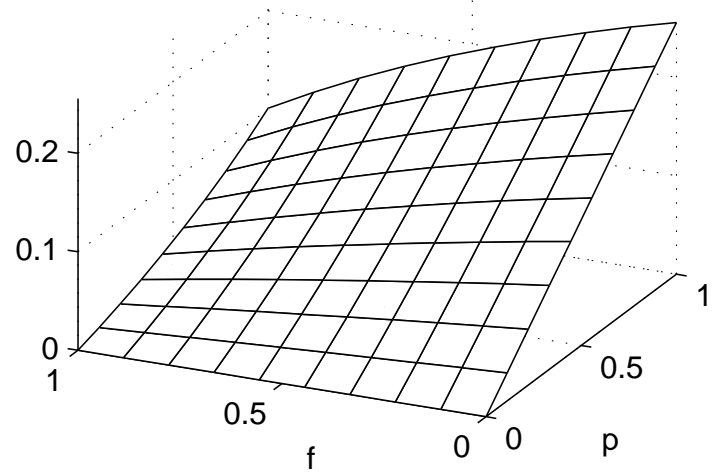

Figure 8: Effects of dual EPL when education is endogenous and parameter $a 1$ is chosen arbitrarily high. STJ and LTJ stand for short term and long term jobs respectively. 
a. Gross Production (endogenous education)

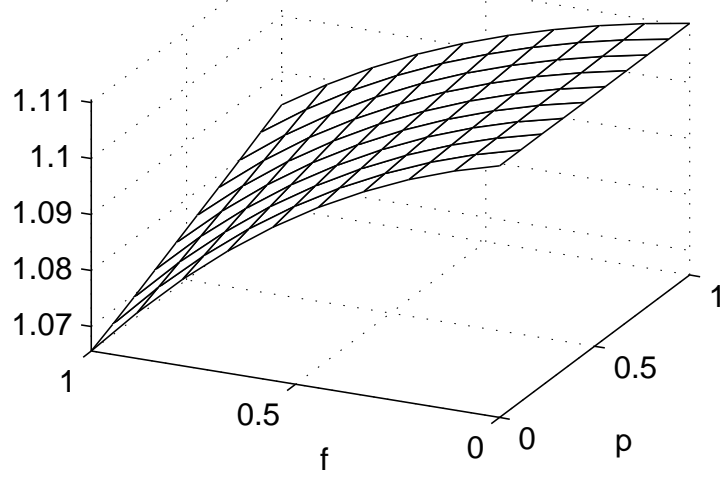

c. Gross Production (exogenous education)

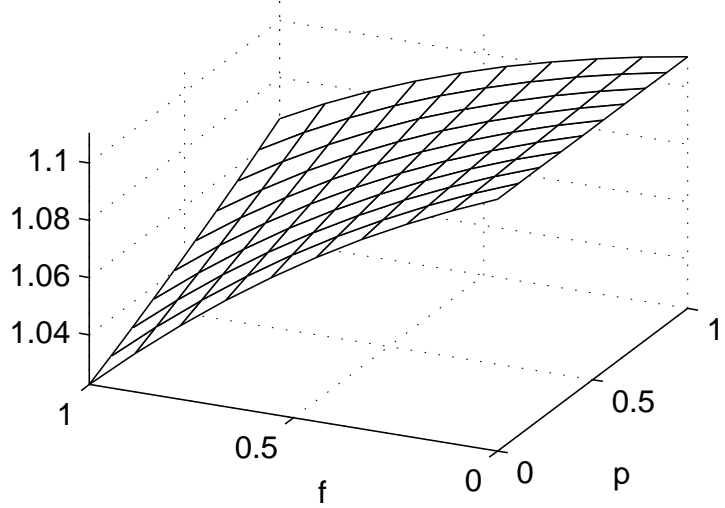

b. Welfare (endogenous education)

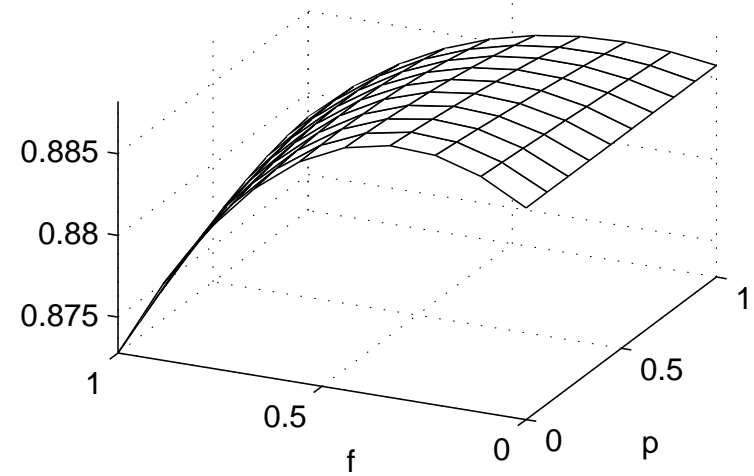

d. Welfare (exogenous education)

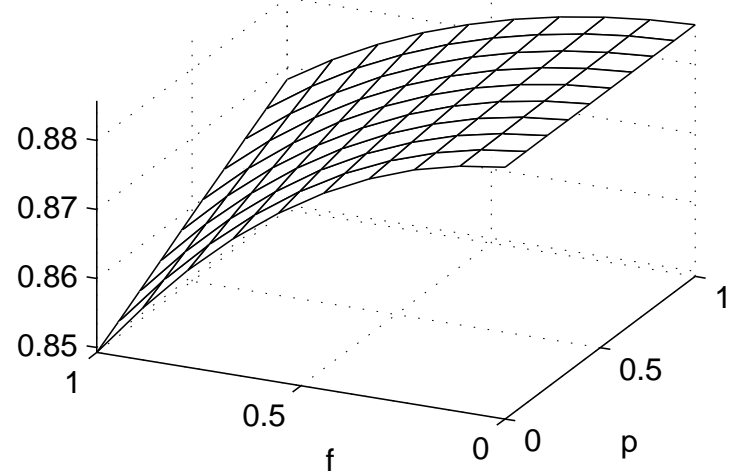

Figure 9: Welfare effects of dual EPL. On the panel the first column depicts the gross production and the second column the production net of vacancy and schooling costs. The first row refers to situations where education is endogenous and the second row to situations where education is exogenous. 


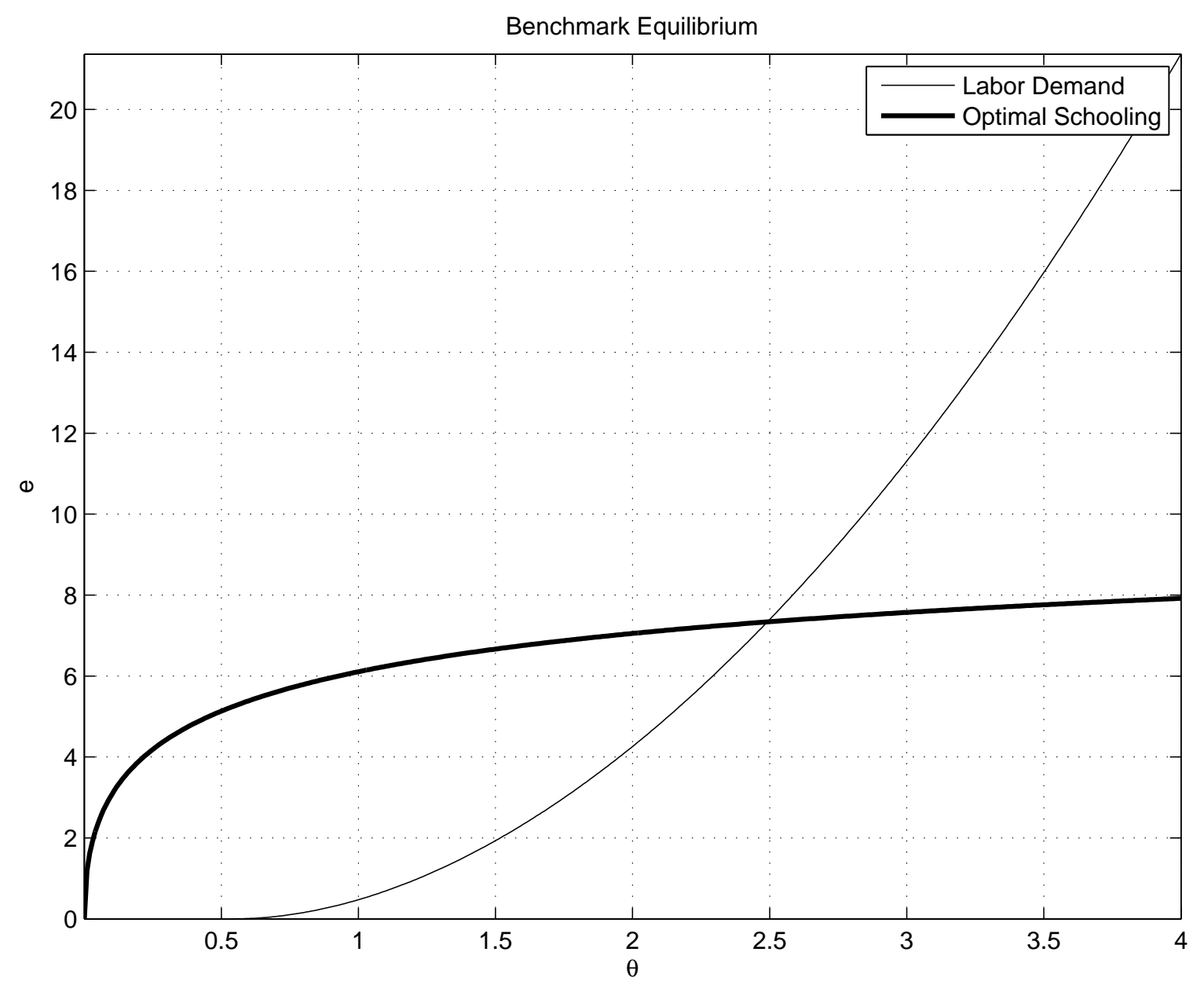

Figure 10: General Equilibrium Implicit Plot for the benchmark case. 